\title{
Physico-Mechanical Properties of Metal Matrix Self-Lubricating Composites Reinforced with Traditional and Nanometric Particles
}

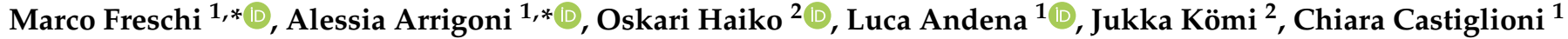 \\ and Giovanni Dotelli ${ }^{1}$ (D)
}

Citation: Freschi, M.; Arrigoni, A.; Haiko, O.; Andena, L.; Kömi, J.; Castiglioni, C.; Dotelli, G. Physico-Mechanical Properties of Metal Matrix Self-Lubricating Composites Reinforced with Traditional and Nanometric Particles. Lubricants 2022, 10, 35. https:// doi.org/10.3390/lubricants10030035

Received: 11 January 2022

Accepted: 27 February 2022

Published: 2 March 2022

Publisher's Note: MDPI stays neutral with regard to jurisdictional claims in published maps and institutional affiliations.

Copyright: (C) 2022 by the authors. Licensee MDPI, Basel, Switzerland. This article is an open access article distributed under the terms and conditions of the Creative Commons Attribution (CC BY) license (https:/ / creativecommons.org/licenses/by/ $4.0 /)$.
1 Department of Chemistry, Materials and Chemical Engineering "Giulio Natta", Politecnico di Milano, Piazza Leonardo da Vinci 32, 20133 Milan, Italy; luca.andena@polimi.it (L.A.); chiara.castiglioni@polimi.it (C.C.); giovanni.dotelli@polimi.it (G.D.)

2 Materials and Mechanical Engineering, Centre for Advanced Steels Research, University of Oulu, Pentti Kaiteran Katu 1, 90570 Oulu, Finland; oskari.haiko@oulu.fi (O.H.); jukka.komi@oulu.fi (J.K.)

* Correspondence: marco.freschi@polimi.it (M.F.); alessia.arrigoni@polimi.it (A.A.); Tel.: +39-0223993232 (M.F.)

\begin{abstract}
Innovative nanostructured materials offer the possibility of enhancing the tribological performance of traditional materials like graphite and molybdenum disulfide $\left(\mathrm{MoS}_{2}\right)$. In this study, the scratch resistance of two different copper powders, dendritic and spherical, and their composites with traditional $\mathrm{MoS}_{2}$, nanometric $\mathrm{MoS}_{2}$, and graphene nanoplatelets was investigated. Metal powder metallurgy was employed to produce composite materials with $5 \mathrm{wt} \%$ and $10 \mathrm{wt} \%$ of each solid lubricant. A ball milling step was employed to grind and mix the matrix copper powder with the lubricants. The use of a cold press combined with the sintering in inert atmosphere at $550{ }^{\circ} \mathrm{C}$ limited the oxidation of the copper and the degradation of the solid lubricants. The so-produced materials were characterized through a variety of techniques such as micro-indentation hardness, electrical resistivity, contact angle wettability, X-ray diffraction, Raman scattering, and scanning electron microscopy. Moreover, micro-scratch tests were performed on both pure copper and composite materials for comparing the apparent scratch hardness and friction coefficients. The scratches were examined with confocal laser scanning microscopy (CLSM), to identify the evolution of the damage mechanisms during the formation of the groove. The results highlighted the important difference between the dendritic and spherical copper powders and demonstrated a way to improve wear behavior thanks to the use of nanometric powders as solid lubricants.
\end{abstract}

Keywords: copper powder; scratch resistance; solid lubricant; nanometric lubricant; composite material; metal powder metallurgy; wear; tribology

\section{Introduction}

Metal matrix composites (MMCs) have attracted great interest thanks to the possibility of satisfying a wide range of requirements by tuning their properties accordingly. MMCs find typically employment in the aerospace, industry, and automotive sectors [1].

The selection of the constituent materials, i.e., the matrix and the second phase, strongly determines the properties of the composite. In particular, suitable second phases can be added in order to impart lubricating properties to the final MMCs, making them interesting candidates for tribological applications.

Liquid lubricants or grease are typically employed to limit friction and wear. However, it is not possible to use them in specific working conditions, such as vacuum, extreme pressure or temperature, in the presence of an electrical current, or in peculiar systems where the continuous supply or collection of the liquid lubricant are not possible, thus limiting their application. In this context, solid lubricants, e.g., graphite and transition metal dichalcogenides (TMDs), offer a valid alternative, thanks to their layered structure, 
which confers lubricity [2,3]. The most commonly employed solid lubricants in industry are graphite and the transition metal dichalcogenides (TMD), particularly molybdenum disulfide $\left(\mathrm{MoS}_{2}\right)[4,5]$.

In graphite, graphitic layers are largely held together by van der Waals forces, which are much weaker than the planar primary bonding forces. Due to their characteristic lamellar structure, humidity or organic vapors are required to facilitate the shearing of the planes, especially when used at low pressures or at high altitude, providing low cohesion. Thus, graphite develops its most favorable lubricating properties in presence of moisture [6]. Metal-impregnated carbon and graphite dispersed in metals have found widespread use in applications at high temperatures [7].

$\mathrm{MoS}_{2}$ is characterized by easy movement of the lamellae thanks to the weak Van der Waals forces between the sulfur layers, and it does not require a humid environment to contribute to decreased friction coefficient and wear $[3,4,6,8]$. As sliding progresses, the motion of the layers is limited, and the lubrication is supplied by the film made of anisotropic, plate-shaped crystallites at the interface between the sliding surfaces [5].

The advance in manipulating 2D-structured materials led to their employment for tribological applications. Nanostructured materials exhibit peculiar properties, improving performances and satisfying more challenging requirements [9-11]. One of the most remarkable nanostructured materials developed in the last decades is graphene. It was employed for a wide range of innovative applications thanks to its outstanding mechanical, electrical, and physical properties. In this context, the use of graphene nanoplatelets can lead to significant improvements in the lubrication field, thanks to their chemical inertness and stability [12-14]. Sarno et al. [15] investigated the different effects and mechanisms arising in tribological systems due to the presence of nano-additives.

Even if the lubricating effect of the TMD is well-known and widely investigated, the nanostructures of this class of materials began to generate interest because of their theoretically estimated superlubricity behavior, reaching friction coefficient values close to zero in particular conditions [11,16] and granting chemical inertia [17].

According to Evans and Senior [18], self-lubricating materials are defined as those which are not damaged when sliding against another surface with no need for an additional lubricant, maintaining efficient velocity and load. These materials have a wide application, especially under extreme conditions such as chemical, aerospace, turbine, cryogenic or radiation environments.

The above-mentioned materials can be considered as a second phase in the production of self-lubricating MMCs. This class of materials is employed in electrical applications to transfer electric power or signals between stationary and rotating components, as in sliding electrical contacts. In this framework, solid lubricants are preferred to liquids, due to temperature and pressure variations of the operative environment and the possibility of being employed as conductive components [5]. For this reason, the extension of the component lifetimes and the increase of their electrical power transmission efficiency have been under the spotlight in recent decades due to the environmental- and energy-related global concerns [19]. Several combinations of matrixes and solid lubricants were considered, and their performances typically depend on the microstructure of the raw materials $[20,21]$, the concentration of second phases [22-24], the applied load to maintain the contact of the mating surfaces [25], their reciprocal speed [26], the electrical current density [27-29], and their temperature and environmental conditions [30-32]. The use of MMCs involves the three mechanisms typically involved in the wear of sliding electrical components, ensuring high wear resistance and the required electrical conductivity [33].

Copper and silver are the most widely investigated materials for conductive selflubricating MMCs thanks to their outstanding electrical conductivity, allowing the employment of the semiconductive phases. In recent decades, copper and carbonaceous phases have attracted scientific research, thanks to their combination of electrical conductivity, mechanical and tribological properties. The different allotropes of carbon that 
have been employed in addition to the copper matrix include graphite [34,35], fibers [36], graphene [37-39], and carbon nanotubes [40].

It was shown that by increasing the percentage of this second phase, the friction coefficient decreases while the hardness usually increases up to a threshold value, after which a reduction is observed. This phenomenon is caused by the distribution of the second phase at the grain boundary of copper, affecting the cohesion of the metal matrix. Indeed, the grain boundary presents the preferential path for cracks formation, and an excess of graphene overly weakens this crucial region. The increased percentage of graphene leads to a lower friction coefficient in wear tests thanks to the abundance of lubricant, matched by deeper wear tracks [39]. The ploughing abrasive wear, delamination and adhesion observed in pure copper samples are mitigated in the composite materials. The uniformly distributed second phase leads to the formation of a more homogeneous tribofilm, improving tribological performance and decreasing the wear rate.

As previously stated, molybdenum disulfide is one of the most used traditional solid lubricants. Its employment with copper was investigated for electrical contacts, brushes, and friction materials characterized by electrical and thermal conductivity [41]. Parallel to carbon-based second phases, a strengthening effect and a decrease of the wear loss are reported for the increased mass fraction of $\mathrm{MoS}_{2}$. The presence of the solid lubricant decreases the friction coefficient thanks to the formation of a lubricating tribo-film between the sliding surfaces [42,43]. The thicker, homogeneous tribo-film protects the composite surface, providing better tribological performances, preventing severe abrasion and delamination, and supporting wear resistance [44,45].

An interesting work by Vincent et al. [46] evaluated porosity and its effect on thermal conductivity of samples produced via powder metallurgy employing dendritic and spherical copper powders. Even if the investigation was limited to thermal conductivity, one attractive result was that the porosity value and distribution were influenced by the morphology of the sintering powder. Inspired by this work, the difference in tribological behavior between dendritic and spherical copper powders was analyzed in the present study.

The abovementioned studies highlight the research interest in copper MMCs. This study aims to analyze the different behaviors of two selected copper powders, dendritic and spherical, and three solid lubricants, namely micrometric molybdenum disulfide $\left(\mathrm{MoS}_{2}\right)$, nanometric molybdenum disulfide $\left(\mathrm{MoS}_{2} \mathrm{n}\right)$ and graphene nanoplatelets (GNP). The composite materials produced via powder metallurgy contained $5 \mathrm{wt} \%$ and $10 \mathrm{wt} \%$ of the second phase. Thermogravimetric analysis was used to determine a suitable temperature for sintering, avoiding thermal degradation of the materials. The possible formation of unwanted phases was investigated by X-ray diffractometry and Raman scattering. As previously stated, copper self-lubricating MMCs can be employed in sliding electrical contacts, hence a first evaluation of electrical resistivity was performed. Sliding electrical contacts employed in aircraft operate at high altitude, and ice formation should be avoided. For this reason, wettability was examined via the static optical contact angle. The tribological behavior of the produced composites was analyzed by scratch test, a methodology typically used on thin films, that can be also employed in wear mechanism evaluation and tribological analysis. Thanks to the different outputs provided by this technique, such as friction coefficient, penetration depth, scratch hardness, it is a useful tool to model the tribological and wear performance of the materials by acting as an elementary process for abrasion wear [47-50].

\section{Materials and Methods}

\subsection{Materials}

Two different commercial copper powders (CP) were considered as conductive matrixes for the composite materials. The first, supplied by Makin Metal Powder (Rochdale, $\mathrm{UK}$ ), was a dendritic powder whose apparent density was $0.7 \mathrm{~g} \mathrm{~cm}^{-3}$, and whose chemical composition is $\mathrm{Cu}>99.6 \%$ with a low percentage $(0.07 \%)$ of $\mathrm{O}_{2}$. According to the producer, $99.1 \%$ of the particles had a dimension lower than $45 \mu \mathrm{m}, 0.8 \%$ had a dimension between 
$45 \mu \mathrm{m}$ and $53 \mu \mathrm{m}$, and $0.1 \%$ had a dimension between $53 \mu \mathrm{m}$ and $75 \mu \mathrm{m}$ [51]. The second $\mathrm{CP}$, supplied by Pometon(Maerne, Italy), was a water-atomized spherical powder. The apparent density was attested to be $2.64 \mathrm{~g} \mathrm{~cm}^{-3}$ and the chemical composition was attested to be $99.94 \%(\mathrm{Cu})$ and $0.06 \%\left(\mathrm{O}_{2}\right)$. A total of $79 \%$ of the particles had a dimension lower than $45 \mu \mathrm{m}$ [52]. The morphologies of the $\mathrm{CP}$, namely dendritic and spherical, were considered.

Molybdenum disulfide $\left(\mathrm{MoS}_{2}\right)$ is one of the traditional solid lubricants used in composite materials. The Sigma-Aldrich(Corporation, St. Louis, MO, USA) powder particles had a layered structure with a size of $6 \mu \mathrm{m}$ and a density of $5.06 \mathrm{~g} \mathrm{~cm}^{-3}$ at $25{ }^{\circ} \mathrm{C}$. A nanometric powder of the same solid lubricant $\left(\mathrm{MoS}_{2}\right)$, with characteristic nominal dimensions of $90 \mathrm{~nm}$ and a purity of $99 \%$, was also investigated in this study. Finally, graphene nanoplatelets (GNP) used as solid lubricant, supplied by Sigma-Aldrich, were supplied in powder form with an apparent bulk density of $0.04 \mathrm{~g} \mathrm{~cm}^{-3}$, a composition of $95 \mathrm{wt} \% \mathrm{C}$, less than $2 \mathrm{wt} \% \mathrm{O}_{2}$, and lateral dimensions declared as higher than $25 \mu \mathrm{m}$.

\subsection{Production Method}

The powders were dried in a muffle oven at $120^{\circ} \mathrm{C}$ for $5 \mathrm{~h}$. The combinations of the two CP powders and the three lubricants, with $5 \mathrm{wt} \%$ and $10 \mathrm{wt} \%$, were ball-milled with zirconia $\left(\mathrm{ZrO}_{2}\right)$ spheres (powder to $\mathrm{ZrO}_{2}$ ratio was 1:10 wt/wt). The grinding and mixing procedure lasted $2 \mathrm{~h}$. The pure copper samples were simply ball milled for $2 \mathrm{~h}$. The milled powders were cold pressed under 2 tons pf load (corresponding to $75 \mathrm{MPa}$ ) for 5 min in a rigid cylindrical die using a manual press, Atlas Manual Hydraulic Press 15T by Specac Ltd. (Orpington, UK). The result was a tablet with a diameter of $13 \mathrm{~mm}$ and a thickness around $3 \mathrm{~mm}$. The tablets were sintered in a slightly reducing atmosphere of $95 \mathrm{vol} \%$ nitrogen and $5 \mathrm{vol} \%$ hydrogen at $550{ }^{\circ} \mathrm{C}$ for $1 \mathrm{~h}$ with a heating ramp of $15^{\circ} \mathrm{C} / \mathrm{min}$ and air-cooled at the end of the process. The main steps of the process are sketched in Figure 1 and the produced samples are listed in Table 1.

\section{COPPER POWDERS}
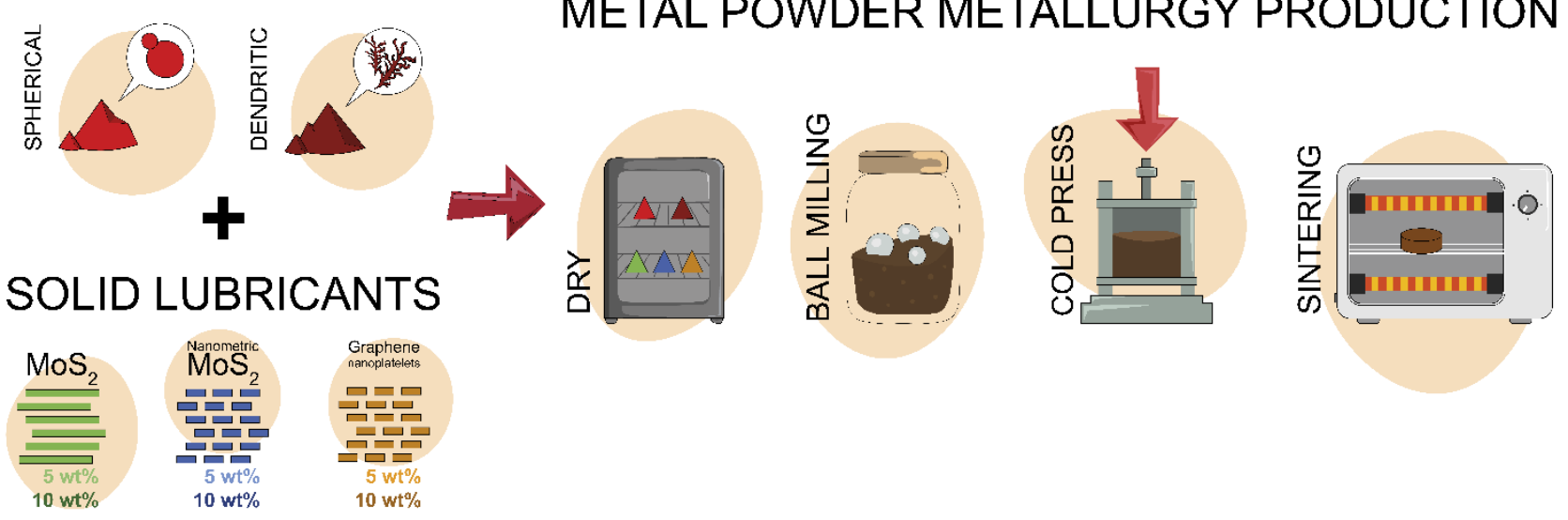

Figure 1. Scheme of the production of the composite material samples.

Table 1. List of the produced composite materials, made of dendritic (D-) and spherical (S-) copper powder matrices and different weight concentrations of $\mathrm{MoS}_{2}$, nanometric $\mathrm{MoS}_{2}$, and graphene nanoplatelets.

\begin{tabular}{lcccc}
\hline Sample ID & Matrix CP & $\begin{array}{c}\mathbf{M o S}_{\mathbf{2}} \text { Content } \\
\mathbf{( w t} \%)\end{array}$ & $\begin{array}{c}\mathbf{M o S}_{\mathbf{2}} \mathbf{n} \text { Content } \\
\mathbf{( w t \% )}\end{array}$ & $\begin{array}{c}\text { GNP Content } \\
\mathbf{( w t \% )}\end{array}$ \\
\hline $\mathrm{D}-\mathrm{Cu}$ & Dendritic & - & - & - \\
$\mathrm{D}-5 \mathrm{MoS}_{2}$ & Dendritic & 5 & - & - \\
$\mathrm{D}-10 \mathrm{MoS}_{2}$ & Dendritic & 10 & - & - \\
$\mathrm{D}-5 \mathrm{MoS}_{2} \mathrm{n}$ & Dendritic & - & 5 & - \\
$\mathrm{D}-10 \mathrm{MoS}_{2} \mathrm{n}$ & Dendritic & - & 10 & - \\
$\mathrm{D}-5 \mathrm{GNP}$ & Dendritic & - & - & 5 \\
\hline
\end{tabular}


Table 1. Cont.

\begin{tabular}{|c|c|c|c|c|}
\hline Sample ID & Matrix CP & $\begin{array}{c}\operatorname{MoS}_{2} \text { Content } \\
(w t \%)\end{array}$ & $\begin{array}{c}\operatorname{MoS}_{2} \text { n Content } \\
(w t \%)\end{array}$ & $\begin{array}{l}\text { GNP Conten } \\
\text { (wt } \%)\end{array}$ \\
\hline D-10GNP & Dendritic & - & - & 10 \\
\hline $\mathrm{S}-\mathrm{Cu}$ & Spherical & - & - & - \\
\hline $\mathrm{S}-5 \mathrm{MoS}_{2}$ & Spherical & 5 & - & - \\
\hline $\mathrm{S}-10 \mathrm{MoS}_{2}$ & Spherical & 10 & - & - \\
\hline $\mathrm{S}-5 \mathrm{MoS}_{2} \mathrm{n}$ & Spherical & - & 5 & - \\
\hline $\mathrm{S}-10 \mathrm{MoS}_{2} \mathrm{n}$ & Spherical & - & 10 & - \\
\hline S-5GNP & Spherical & - & - & 5 \\
\hline S-10GNP & Spherical & - & - & 10 \\
\hline
\end{tabular}

\subsection{Thermogravimetric Analysis}

Thermogravimetric analysis (TGA) was carried out in a nitrogen inert atmosphere using an Extras 6000 TG/DTA 6300 by Seiko (Chiba, Japan), from room temperature to $1000{ }^{\circ} \mathrm{C}$. Concerning the GNP and the $\mathrm{MoS}_{2}$ powders, TGA was intended to determine the suitable temperature for the sintering step, avoiding the degradation of the lubricant in the copper matrix.

\subsection{X-ray Diffractometry}

XRD analysis allowed us to investigate the presence of reaction products or impurities originating from the high temperature during the sintering process. The analysis was conducted using a D8 Advance diffractometer by Bruker Corporation (Billerica, MA, USA), in the $10-80^{\circ} 2 \theta$ range, with a step of $0.02^{\circ}$ and a time per step of 1 s. Copper $K \alpha(1.54 \AA)$ was used as radiation source.

\subsection{Raman Spectroscopy}

To obtain the Raman scattering spectra, a solid-state neodymium-yttrium aluminum garnet laser, with a wavelength of $532 \mathrm{~nm}$ at a power of $5 \mathrm{~mW}$, was employed. Three 20 $s$ acquisitions were performed using a Jobin Yvon LabRAM HR800 Raman spectrometer by HORIBA (Kyoto, Japan), with a 50× objective-microscope model BX41 (Olympus Corporation, Tokyo, Japan).

\subsection{Static Optical Contact Angle}

The static optical contact angle (OCA) measurement determined the hydrophilic or hydrophobic behavior of the material. Hydrophilic behavior is undesired when the working temperature is close to $0{ }^{\circ} \mathrm{C}$ because it enhances ice formation, which can compromise the performance of the tribological system. An OCA 20 by Dataphysics Instruments $\mathrm{GmbH}$ (Filderstadt, Germany), with a CDD video-camera analyzed and measured the angle between the prepared tablets and a $3 \mu \mathrm{L}$ drop of water, released using a $500 \mu \mathrm{L}$ Hamilton syringe. The analysis was carried out 10 times to define the average contact angle of each sample.

\subsection{Electrical Resistivity}

As mentioned in the introduction section, copper self-lubricating MMCs are employed in electrical contacts. One essential property of the selected composite is the low electrical resistivity. In this study, the measurement of electrical resistance was performed using a resistance meter, model 2841 by BK Precision (YorbaLinda, CA, USA). After measuring electrical resistance $(R)$, the electrical resistivity $(\rho)$ was calculated by the second Ohm's law, Equation (1) [53], where the geometry parameters were the width $(w)$ and thickness $(t)$ of the sample and the distance $(d)$ between the clamps of the resistance meter, as sketched in Figure 2.

$$
\rho=R \cdot \frac{w \cdot t}{d}
$$




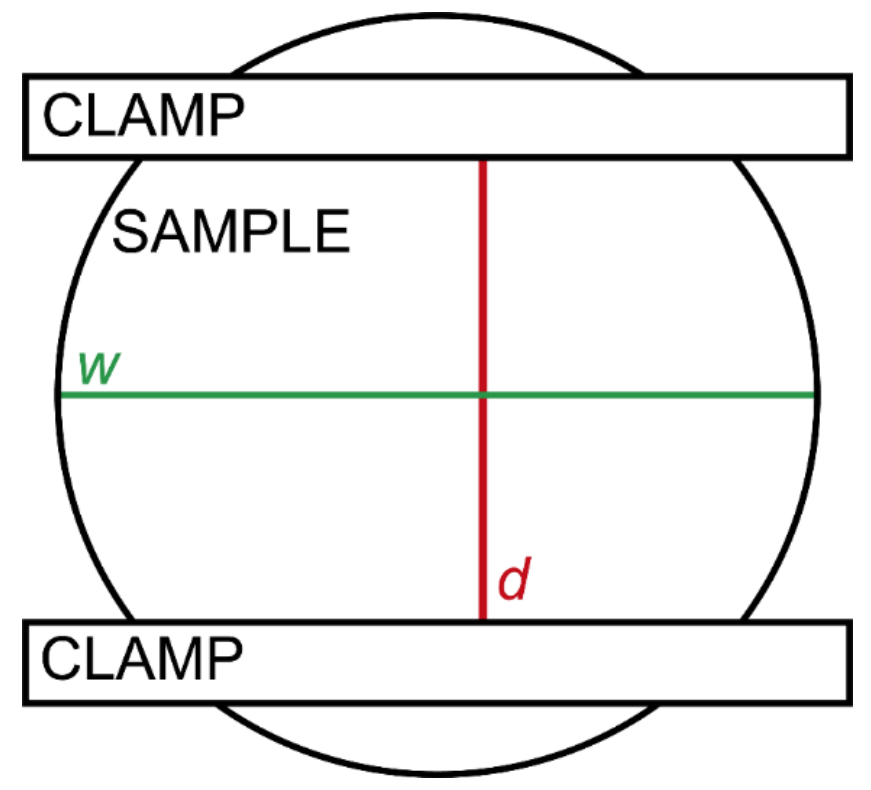

Figure 2. Scheme of electrical resistivity measurement, where the clamp distance $(d)$ and the sample width $(w)$ are highlighted.

\subsection{Micro-Indentation Hardness}

The micro-indentation hardness test was performed by the Microhardness Tester FM700, by TECMET 2000 S.R.L., Corsico, Italy, using a Vickers indenter with an angle of $136^{\circ}$, a load of $0.5 \mathrm{kgf}$ and a dwell time of $15 \mathrm{~s}$. The resulting Vickers hardness (HV) for each produced composite was calculated as the average of three measurements evaluated $\mathrm{T}$ three different points along the diameter of the tablet.

\subsection{Micro-Scratch Test}

The micro-scratch test characterizes the capability of a material to endure scratches and abrasion caused by sharp objects. The measurement was performed on the tablets using a Microscratch tester by CSM Instruments SA(Needham, MS, USA): employing a Rockwell-type diamond indenter, having a $200 \mu \mathrm{m}$ tip radius and $120^{\circ}$ apex angle. The indenter slides with a constant velocity of $30 \mathrm{~mm} \mathrm{~min}^{-1}$ across the sample surface, creating a scratch along a straight path of $3 \mathrm{~mm}$ under a constant normal force (Fn) of $12 \mathrm{~N}$. Ten parallel scratches, $1 \mathrm{~mm}$ apart from each other, were performed on each sample. The outputs of the measurements were the tangential force $(\mathrm{Ft})$ and the penetration depth $(\mathrm{Pd})$, both evaluated with a frequency of $30 \mathrm{~Hz}$. The apparent friction coefficient $(\mu)$ and the micro-scratch hardness (Hs) were calculated according to Equation (2) and Equation (3), respectively, where Ac is the projected load bearing area, which is considered, for metallic materials, as half of the projected area of the penetrated indenter for a given depth [48]. A scheme of the test parameters is reported in Figure 3.

$$
\begin{gathered}
\mu=\frac{\mathrm{Ft}}{\mathrm{Fn}} \\
\mathrm{Hs}=\frac{\mathrm{Fn}}{\mathrm{Ac}}
\end{gathered}
$$

\subsection{Confocal Laser Scanning Microscopy}

The scratches were analyzed using laser confocal scanning microscope VK-X200 from Keyence Corporation(Osaka, Japan). Compressed air was employed to clean the samples' surfaces before the analysis. The acquired images were analyzed using VK Analyzer Plus software, measuring the groove area $\left(\mathrm{A}_{\mathrm{g}}\right)$ and the ridge area $\left(\mathrm{A}_{\mathrm{r}}\right)$, as sketched in Figure 4 . This led to the calculation of three parameters: first, the wear volume $\mathrm{Wv}$, by 
Equation (4) along the scratch length (l) of $3 \mathrm{~mm}$; second, the specific wear rate (W), calculated by Equation (5), where the applied normal load (Fn) is equal to $12 \mathrm{~N}$; and third, the dimensionless wear coefficient (k), from the Archard model [54], which relates wear volume (Wv), scratch hardness (Hs), sliding distance, and normal force via Equation (6).

$$
\begin{gathered}
\mathrm{Wv}=\left(\mathrm{A}_{\mathrm{g}}-\mathrm{A}_{\mathrm{r}}\right) * 1 \\
\mathrm{~W}=\frac{\mathrm{Wv}}{1 * \mathrm{Fn}} \\
\mathrm{k}=\frac{\mathrm{Wv} * \mathrm{Hs}}{1 * \mathrm{Fn}}
\end{gathered}
$$

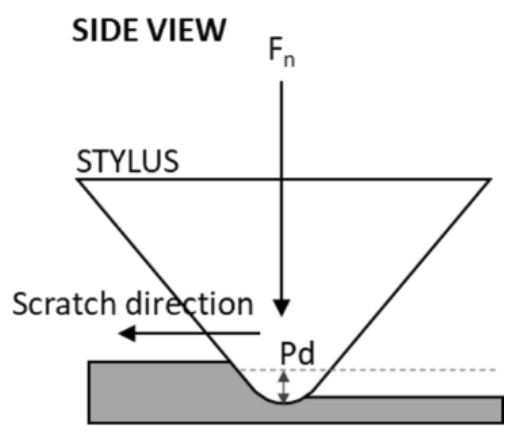

TOP VIEW

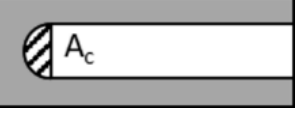

Figure 3. Scheme of the micro-scratch test parameters.

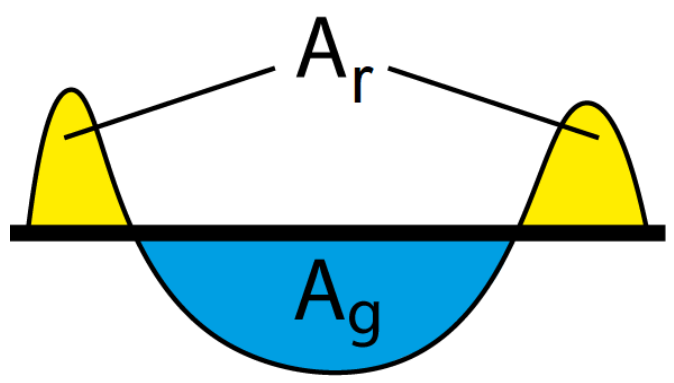

Figure 4. Sketch of the groove area $\left(A_{g}\right)$ in blue and the ridges area $\left(A_{r}\right)$ in yellow.

\subsection{Scanning Electron Microscopy}

Scanning Electron Microscopy (SEM) was performed with an accelerating voltage of $5.00 \mathrm{kV}$ using a Zeiss EVO 50 EP/LZ4 Pentafet to acquire images of the scratches at $800 \times, 5000 \times$, and $10,000 \times$. The magnified images allowed us to better understand the wear mechanisms of the composites.

\section{Results and Discussion}

\subsection{Thermogravimetric Analysis}

The results of the thermogravimetric analysis are reported in Figure 5. The copper powders showed a low weight loss $(<1 \%)$ in the tested temperature range $\left(25-900{ }^{\circ} \mathrm{C}\right)$. The $\mathrm{MoS}_{2}$ and $\mathrm{MoS}_{2} \mathrm{n}$ curves exhibited similar behaviors, reaching a weight loss of $96 \%$ and $97 \%$, respectively. However, a higher weight loss was observed in the micrometric powder (green curve) from room temperature up to $150{ }^{\circ} \mathrm{C}$, probably due to higher moisture content that evaporated in this temperature range. The GNP curve (orange) showed a 
soft and constant weight loss until $600^{\circ} \mathrm{C}$, then a strong decrease in weight was observed, probably due to thermal degradation of graphene layers. The results of the analysis were considered to select a proper sintering temperature, namely $550{ }^{\circ} \mathrm{C}$, to avoid solid lubricant degradation and possible chemical reaction with the copper matrix, while at the same time guaranteeing the sintering process.

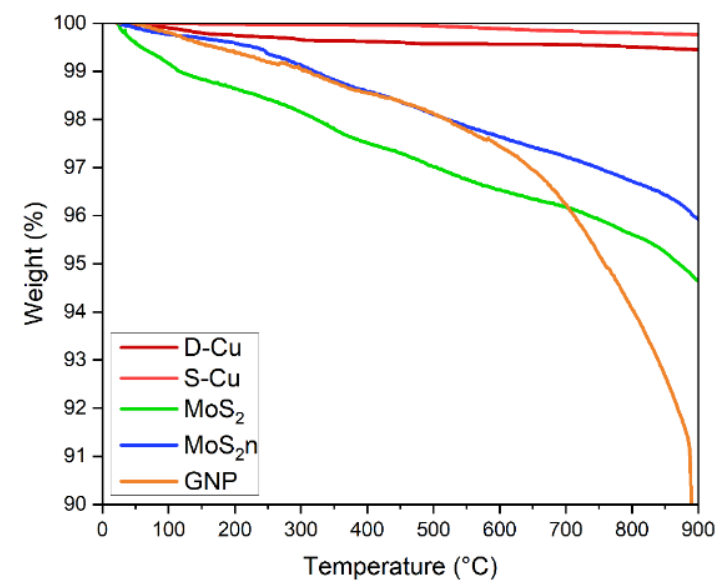

Figure 5. Thermogravimetric analysis results of the copper and solid lubricants powders.

\subsection{X-ray Diffractometry}

One of the techniques employed to detect the presence of unwanted phases that may arise from the sintering process or oxidation of the powders is X-ray diffractometry. Figure 6 reports the diffractograms of the set of (A) dendritic samples and (B) spherical samples. No phases but the copper, molybdenum disulfide and carbon were detected, giving a sign that no crystalline phases were produced during sintering. In both the charts the typical reflections of copper at $43^{\circ}\left(\begin{array}{lll}1 & 1 & 1\end{array}\right), 51^{\circ}\left(\begin{array}{lll}2 & 0 & 0\end{array}\right)$ and $74^{\circ}\left(\begin{array}{lll}2 & 2 & 0\end{array}\right)$ [55], are visible for all the samples. The $\mathrm{MoS}_{2}$ main reflection at $14^{\circ}$ corresponds to the $\left(\begin{array}{ll}0 & 0\end{array}\right)$ planes [56,57] and any relevant difference was detected between the micrometric and the nanometric powder. The samples with graphene nanoplatelets as the solid lubricant show the characteristic carbon reflection at $26^{\circ}\left(\begin{array}{lll}0 & 0 & 2\end{array}\right)$ [58], which is more intense in spherical-copper samples, probably due to a different interaction between the spherical copper matrix and the solid lubricant with respect to the dendritic copper that led to a lower deterioration of the layers during the ball-milling process.
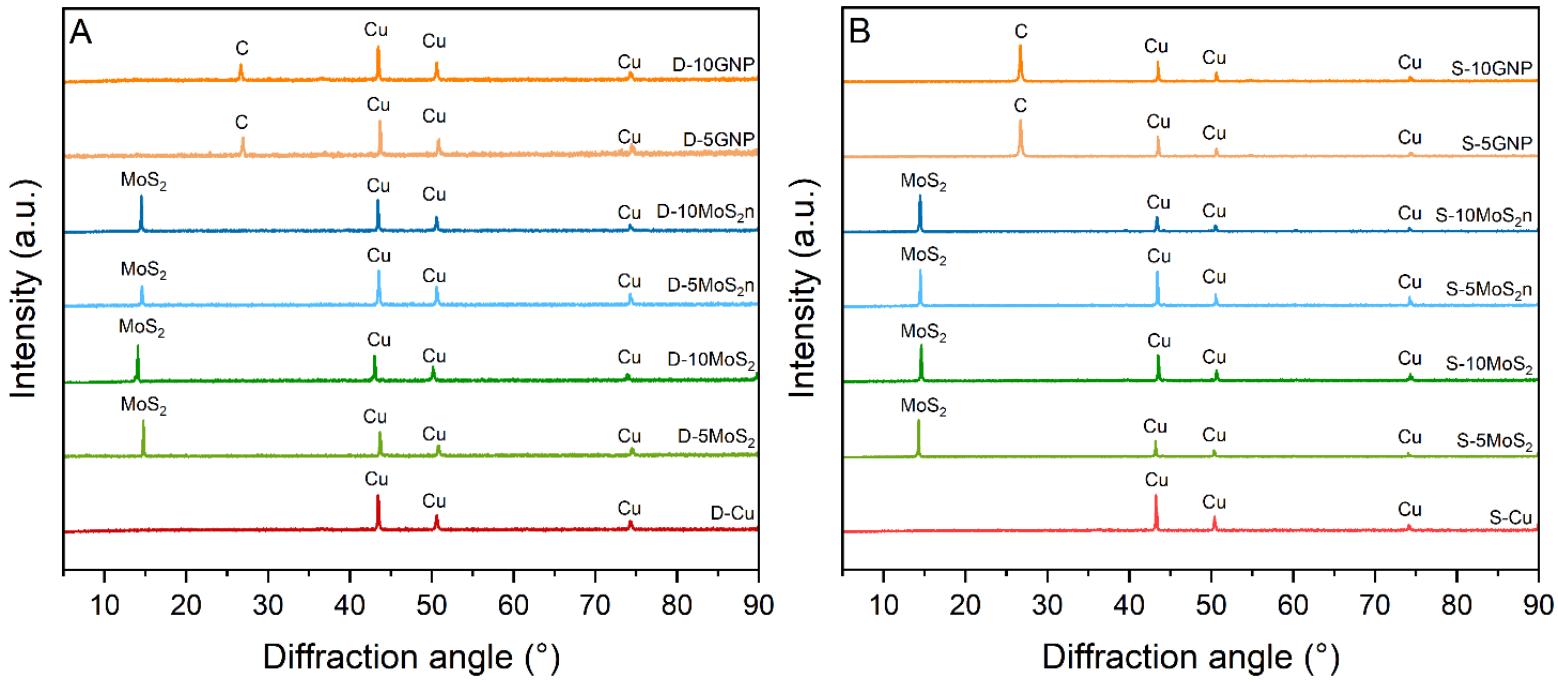

Figure 6. XRD diffractograms of the set of (A) dendritic copper and (B) spherical copper. 


\subsection{Raman Scattering}

Raman spectroscopy was performed on the samples of pure copper and composites with $10 \mathrm{wt} \%$ of solid lubricants. This analysis aims to investigate the composition and to assess the possible development of unwanted species undetected by the X-ray diffractometry. In Figure 7, the Raman spectra of the two copper sets are shown.
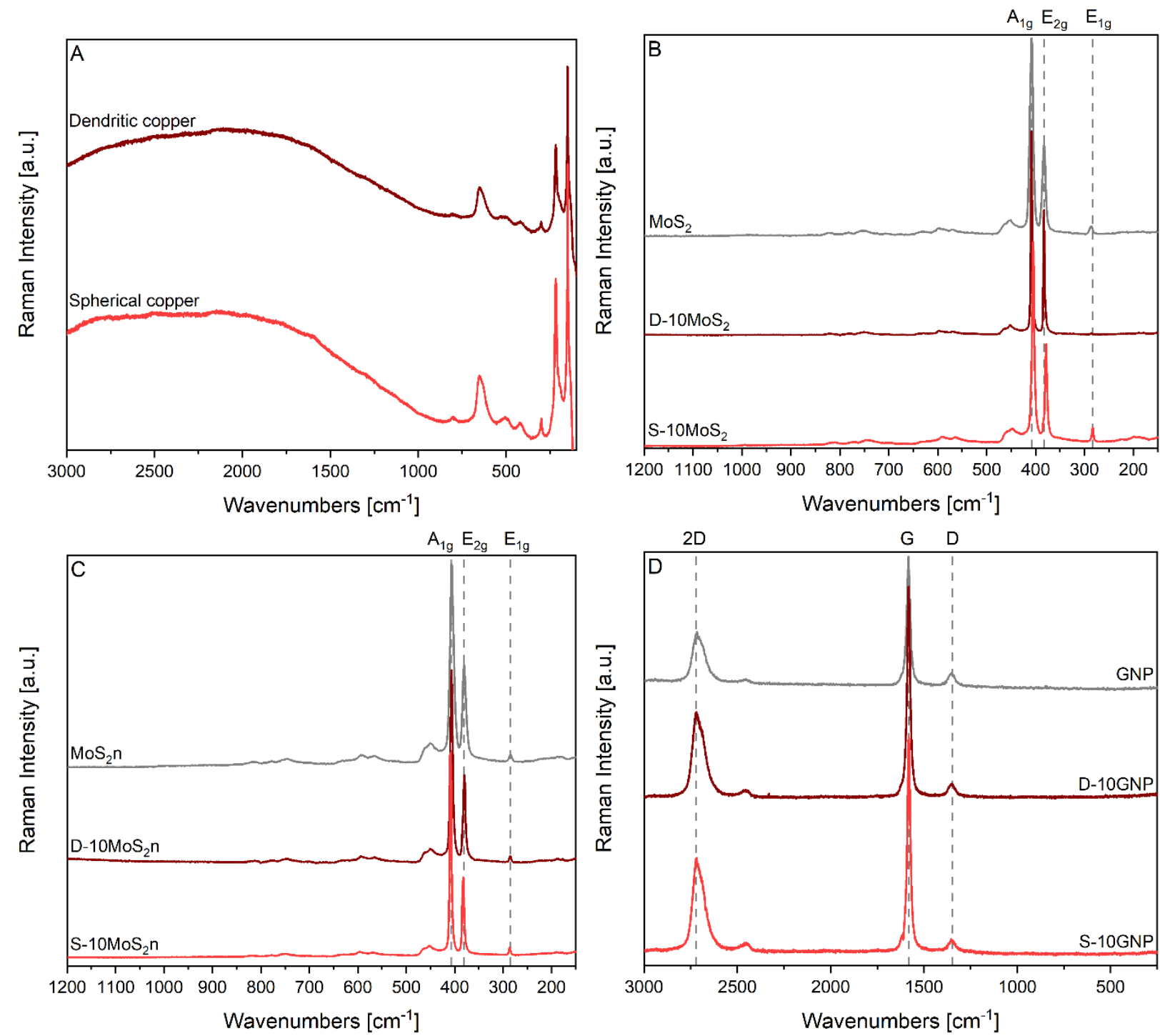

Figure 7. Experimental Raman spectra of (A) the dendritic and spherical copper samples; (B) the dendritic and spherical composite samples containing $\mathrm{MoS}_{2}$ and $\mathrm{MoS}_{2}$ as a reference; (C) the dendritic and spherical composite samples containing nanometric $\mathrm{MoS}_{2}$ and $\mathrm{MoS}_{2}$ nanometric powder as a reference; (D) the dendritic and spherical composite samples containing graphene nanoplatelets and graphene nanoplatelet powder as a reference.

Experimental Raman spectra of $\mathrm{Cu}$ samples, Figure 7A-for both dendritic and spherical copper-show a spectral pattern compatible with the presence of oxidized copper. Indeed, Raman peaks assigned to copper oxides can be detected (e.g., $\mathrm{Cu}_{2} \mathrm{O}$ appears at 151, $\left.218,649 \mathrm{~cm}^{-1}\right)[59,60]$.

In the $\mathrm{MoS}_{2}$ and $\mathrm{MoS}_{2}$ nanometric powder Raman spectra, Figure 7B, C, the in-plane $E_{2 g}$ at $382 \mathrm{~cm}^{-1}$ and the out-of-plane $A_{1 \mathrm{~g}}$ at $407 \mathrm{~cm}^{-1}$ Raman modes of $\mathrm{MoS}_{2}$ exhibited the strongest signals of the whole spectra, as expected [61-63]. The $\mathrm{E}_{1 \mathrm{~g}}$ mode near $286 \mathrm{~cm}^{-1}$ was also present [62]. The number and wavenumbers of the observed peaks confirmed that we were in presence of $\mathrm{MoS}_{2}$-containing copper samples and indicated that the $\mathrm{MoS}_{2}$ structure 
was almost unperturbed when blended with copper, Figure 7B, C. The possible presence of copper sulphates was also investigated. The strongest Raman peaks of these species are expected around $470 \mathrm{~cm}^{-1}$ for CuS [64,65], $512 \mathrm{~cm}^{-1}$ for $\mathrm{CuS}_{2}$ [66] and $1100 \mathrm{~cm}^{-1}$ for $\mathrm{CuSO}_{4}$ [67]. The absence of these peaks in all $\mathrm{MoS}_{2}$-containing spectra suggests that copper sulphates did not develop during processing.

The samples containing graphene nanoplatelets, namely D-10GNP and S-10GNP, as shown in Figure 7D, show spectral features of graphene, such as (i) the sharp G mode at $1580 \mathrm{~cm}^{-1}$, (ii) the $2 \mathrm{D}$ mode at $2700 \mathrm{~cm}^{-1}$ and (iii) the $\mathrm{D}$ band at $1350 \mathrm{~cm}^{-1}$ [68]. The origin of the D-band is ascribed to structural disorder or the presence of defects. As its intensity is strongly affected by the contribution of graphene edges, this band is a marker of confinement and hence of the presence of small graphene domains. For this reason, its presence in all the Raman spectra confirms that the graphene platelets have average sizes in the nanometer scale [68,69]. Adding layers of graphene in stacks modifies the shape of the $2 \mathrm{D}$ band. It evolves from symmetric features typical of single layer graphene to an asymmetric shape with a sharp maximum on the higher energy side, approaching the typical feature of graphite [70]. The fact that the 2D band detected in all samples has an asymmetric shape indicates that, as expected, nanoplatelets were formed by several graphene layers.

\subsection{Static Optical Contact Angle}

A static optical contact angle measurement was performed to evaluate the wettability of the composites; the results are reported in Figure 8. Pure copper samples exhibited hydrophobic behavior, with contact angles of $132^{\circ}$ (dendritic copper) and $136^{\circ}$ (spherical copper). The introduction of the second phases determined the slight decrease of the contact angle. Similar behaviors were observed in the dendritic and spherical sets: the sample with $5 \mathrm{wt} \%$ of $\mathrm{MoS}_{2}$ was more hydrophobic than the sample with $10 \mathrm{wt} \%$ of $\mathrm{MoS}_{2}$. The difference due to higher solid lubricant concentration was not visible to the same extent for $\mathrm{MoS}_{2} \mathrm{n}$ and GNP. Samples S-5GNP and S-10GNP exhibited the lowest contact angles, $99^{\circ}$ and $96^{\circ}$, respectively, showing a different interaction between the spherical copper matrix and the lubricant with respect to the dendritic samples. All the samples exhibited hydrophobic behavior, with contact angles ranging from $96^{\circ}$ (S-10GNP) to $136^{\circ}(\mathrm{S}-\mathrm{Cu}$ ).
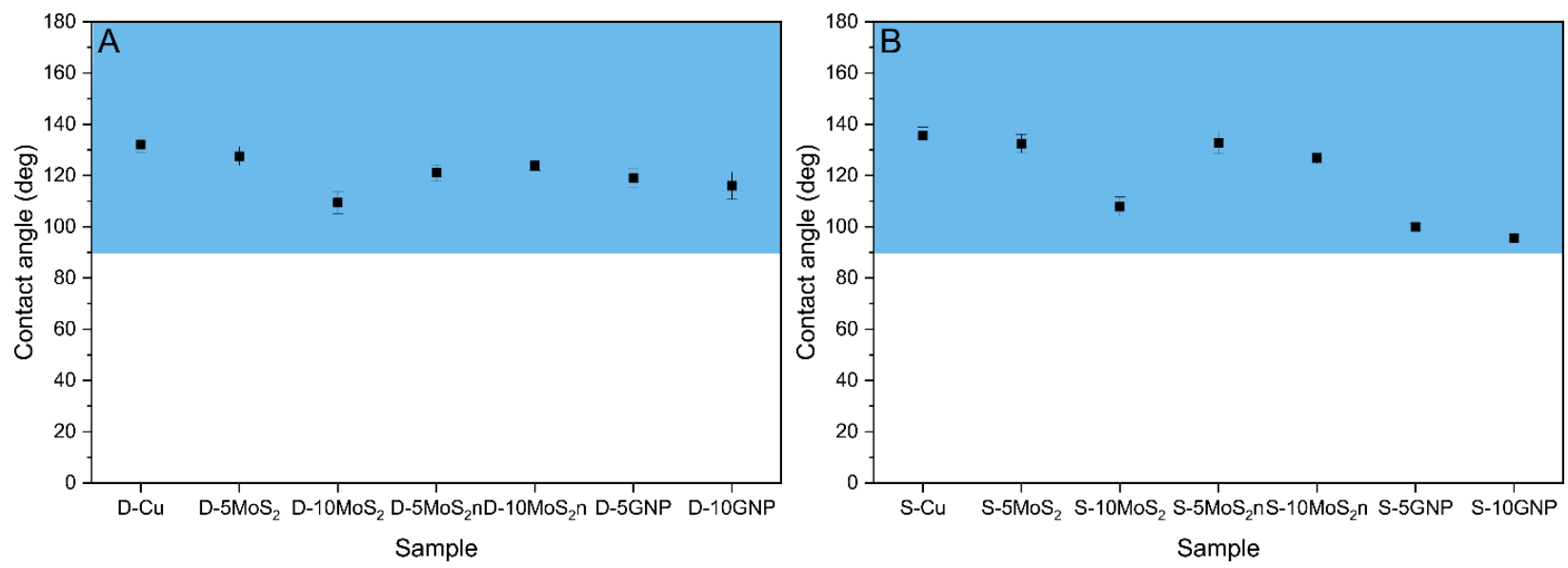

Figure 8. Static optical contact angle measurements of (A) dendritic copper-based and (B) spherical copper-based samples.

\subsection{Electrical Resistivity}

The electrical resistivity of copper tablets was higher than what has been reported in literature for pure copper [71], probably due to intrinsic porosity in the samples. The electrical resistivity values of the dendritic and the spherical samples reported in Figure 9 were in the same order of magnitude (130-290 $\mathrm{n} \Omega \mathrm{m}$ ), except for the GNP samples, whose values ranged from $51 \mathrm{n} \Omega \mathrm{m}$ (D-5GNP) to $96 \mathrm{n} \Omega \mathrm{m}$ (S-5GNP). The spherical structure 
seemed to hinder good compaction, leading to a higher void presence and higher electrical resistivity compared to the same samples of the dendritic set. The presence of dendritic branches may support the creation of a metallic network that presents a preferential path for electrical conduction. The increasing percentage of solid lubricant determined, in the $\mathrm{MoS}_{2}$ and $\mathrm{MoS}_{2} \mathrm{n}$ samples, an increase of the electrical resistivity due to the higher amount of the semiconductive phase. The electrical conductivity of the graphene nanoplatelets and their ease of exfoliation with respect to molybdenum disulfide layers led to a general decrease of the electrical resistivity.
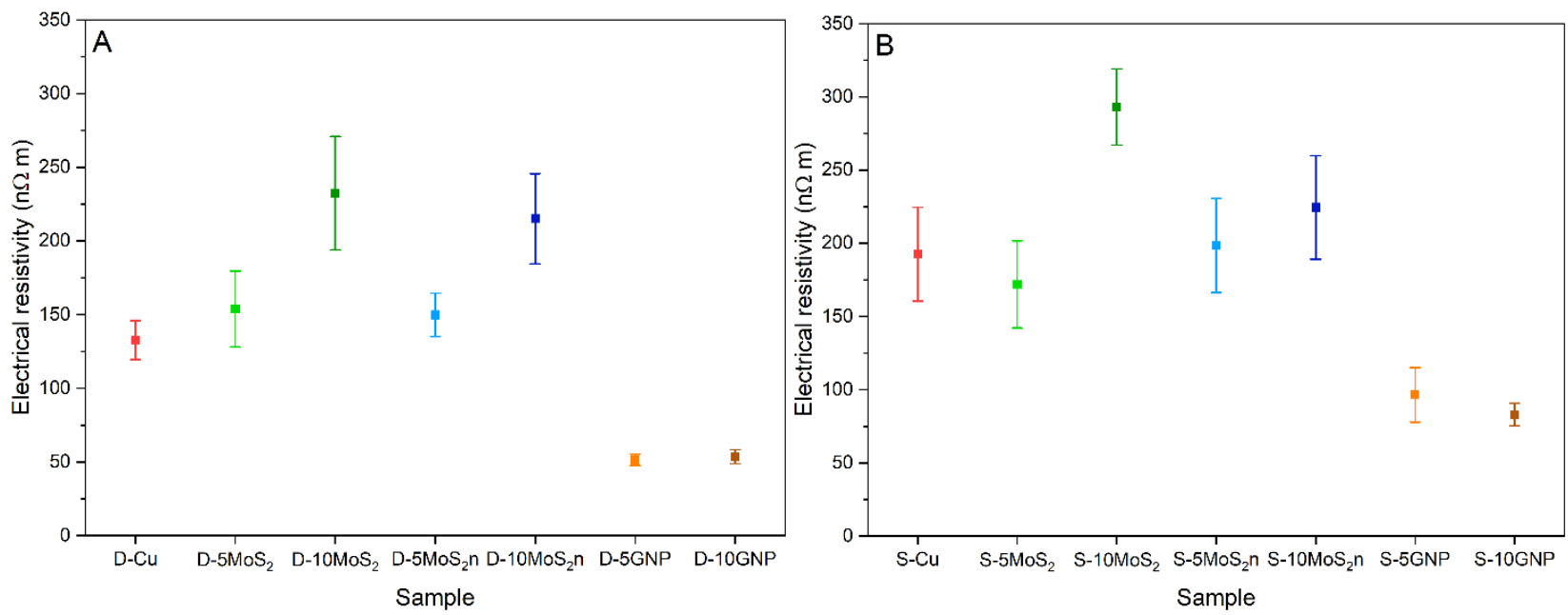

Figure 9. Electrical resistivity results evaluated for (A) dendritic copper-based and (B) spherical copper-based samples.

\subsection{Micro-Indentation Hardness}

The micro-indentation hardness results are reported in Figure 10. Considering the dendritic set, Figure 10A, the introduction of both micrometric and nanometric $\mathrm{MoS}_{2}$ determines a slight reduction of indentation hardness with respect to pure copper. Increasing the percentage of solid lubricant, a slight strengthening effect was measured, as previously reported in the literature $[43,72,73]$. As stated in the introduction, a strengthening effect can be found due to the presence of graphene in the copper matrix [37-39]. The indentation hardness values obtained in this study were largely below those measured for the $\mathrm{MoS}_{2}$ composites, probably due to an excess of solid lubricant. The comparison between the dendritic and the spherical copper powder sets highlights a general decrease of values in the spherical copper-based samples. One viable explanation is bad compaction during the production process that hindered the creation of a strong and homogeneous metallic network, leading to higher porosity within the material.

\subsection{Micro-Scratch Test}

Ten scratches were performed on each sample; the mean values measured for the apparent friction coefficient and calculated for the scratch hardness are reported in Figure 11. The micro-scratch hardness values were in good agreement with the Vickers hardness values, as previously observed on other materials [48]. The presence of the solid lubricant affected both the friction coefficient, with a decrease from 0.75 in the pure copper samples to values that ranged from 0.35 to 0.50 for the dendritic copper composites and more constant values around 0.40 for the spherical copper composites. The best mix to decrease wear combines a low coefficient of friction and a high scratch hardness, a goal obtained by the $\mathrm{D}-10 \mathrm{MoS}_{2}$ and D-10MoS 2 samples on one hand, and by $\mathrm{S}-10 \mathrm{MoS}_{2} \mathrm{n}$ and $\mathrm{S}-5 \mathrm{MoS}_{2} \mathrm{n}$ on the other. 

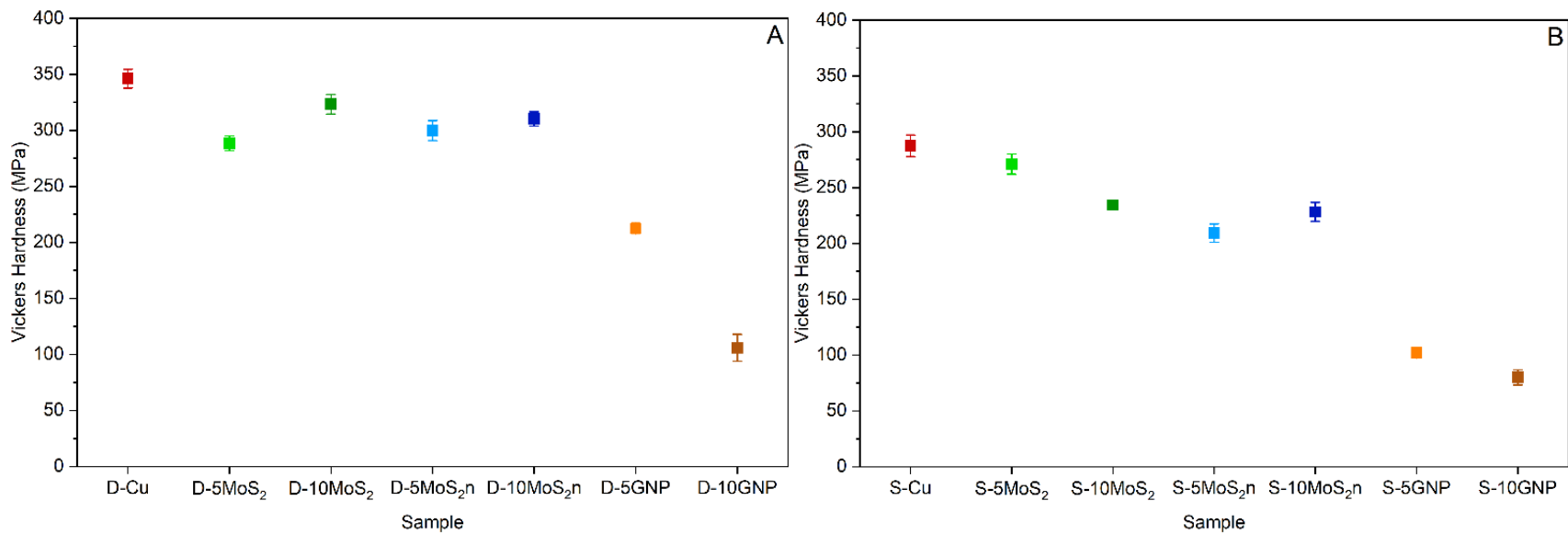

Figure 10. Micro-indentation hardness tested for (A) dendritic copper-based samples and (B) spherical copper-based samples.
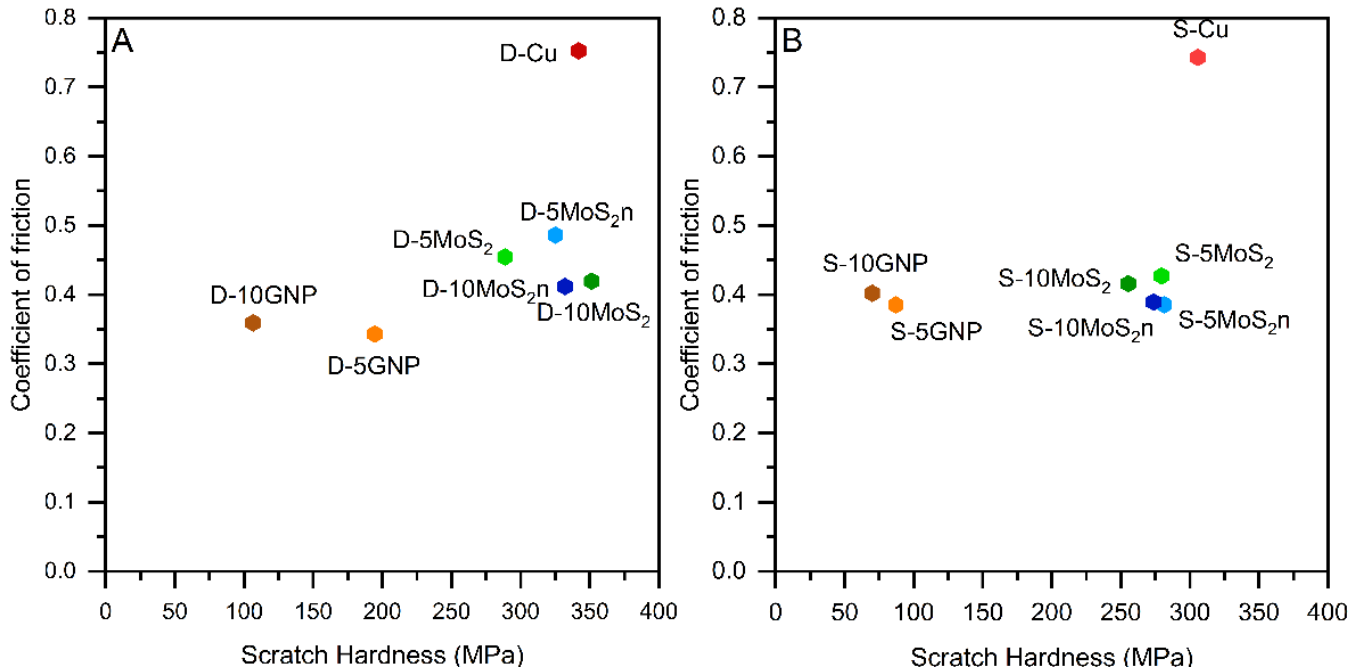

Figure 11. Apparent coefficient of friction vs. scratch hardness results from micro-scratch tests of (A) dendritic copper-based samples and (B) spherical copper-based samples.

The most remarkable variations in the dendritic set were due to the increase of the $\mathrm{MoS}_{2}$ and $\mathrm{MoS}_{2} \mathrm{n}$ percentages, which led to a decreased friction coefficient and an increased scratch hardness. In the spherical set, the same trend was observed, due to the presence of the nanometric $\mathrm{MoS}_{2}$, while the effect of the lubricant percentage was limited.

The GNP composites exhibited a strong decrease of scratch hardness due to the soft agglomerates of the solid lubricant, but this did not correspond to a sensible decrease of the friction coefficient with respect to the micrometric and nanometric $\mathrm{MoS}_{2}$.

The ratio of the penetration depth $(\mathrm{Pd})$ and the calculated radius $(\mathrm{a})$ of the contact area was defined as the degree of penetration (Dp) [74,75]. It gives information on both wear severity and wear mechanisms. The Dp is plotted as a function of distance in Figure 12. The GNP composites with $5 \mathrm{wt} \%$ and $10 \mathrm{wt} \%$, underwent more severe wear with respect to the other materials, which showed an initial increase of the Dp due to the penetration of the tip and a subsequent slight decrease, reaching a plateau with a constant value of Dp. Even if it is not possible to identify a priori the wear mechanism by considering only the Dp, it is a first indication that the wear mechanism is relatively unchanged during the scratch test. 

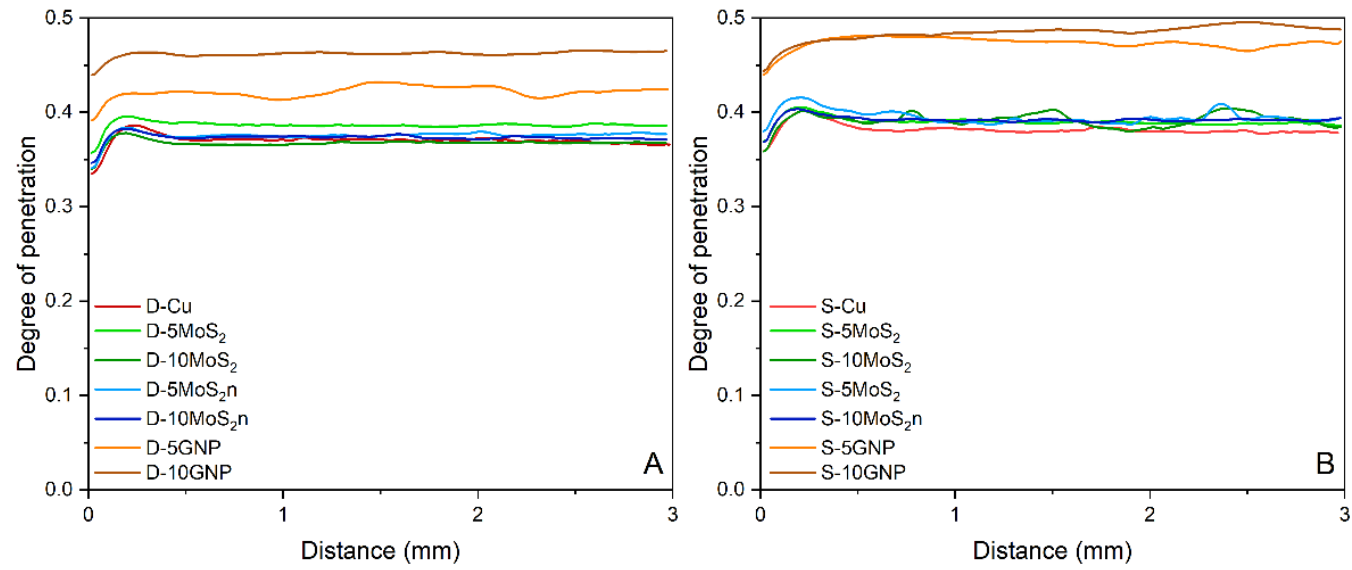

Figure 12. Degree of penetration of (A) dendritic copper-based samples and (B) spherical copperbased samples.

\subsection{Confocal Laser Scanning Microscopy}

The images from the confocal laser scanning microscopy (CLSM), reported in Figure 13, highlight the surface topography within the scratches for both the pure dendritic and spherical coppers. Considering the dendritic copper-based set (on the left of Figure 13): micro-cracks were found within the scratches in the pure copper sample, caused by the tensile loading stress behind the indenter; the defects were less pronounced in the D$5 \mathrm{MoS}_{2}$ sample and disappeared by increasing the solid lubricant percentage, providing evidence of the lubricating effect and the protection of the surface. The presence of GNP determined an irregular track, as was noted from examination of the two bottom images, and a high formation of flake-like debris that grew with the percentage of the solid lubricant. Considering the scratches in the spherical copper-based samples on the right in Figure 13, all the samples were characterized by a higher flake-like debris formation and the presence of more prominent ridges with respect to the corresponding samples of the dendritic set.

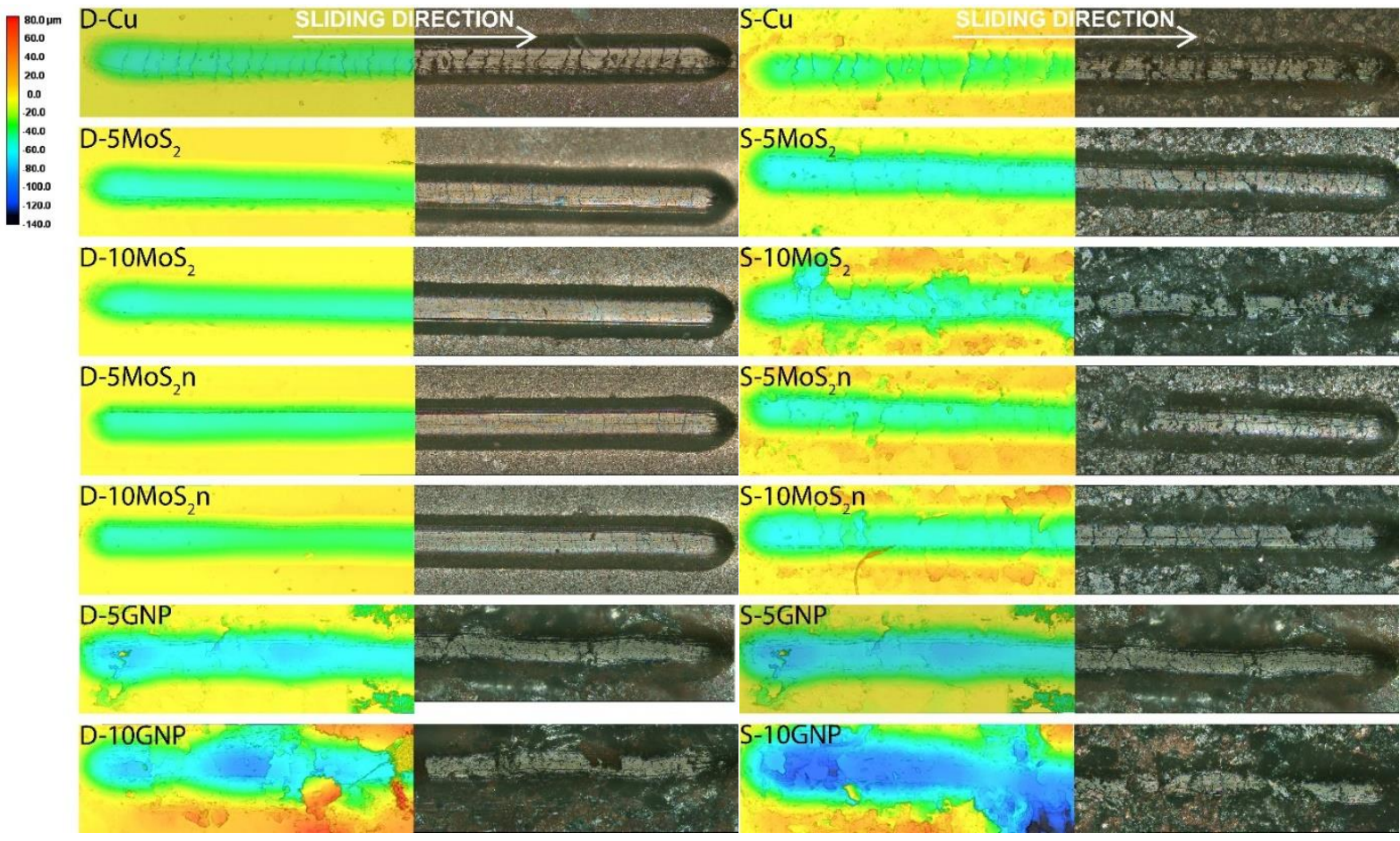

Figure 13. CLSM and optical microscopy images of the scratches for (left) dendritic copper and (right) spherical copper samples. 
The sliding wear plastically deformed all the tested materials. Greater adhesion and tensile loading can be identified as the main phenomena responsible for micro-crack formation in pure copper samples. A transition to an abrasive mechanism is compatible with the parallel grooves located in the scratching of the composite materials. Considering the dendritic set, samples containing $\mathrm{MoS}_{2}$ and $\mathrm{MoS}_{2} \mathrm{n}$ were characterized by the absence of debris and the wedging and ploughing mode is the plausible abrasive mechanism. The samples containing GNP were surrounded by flake-like debris generated during flaking abrasion. The spherical set of composites was generally characterized by the presence of flake-like debris, the number and dimension of which increases for a higher content of micrometric and nanometric $\mathrm{MoS}_{2}$. A more severe flaking abrasive mechanism was observed for samples containing GNP: flakes were more abundant, and the scratch track was deeper with respect to the other composites.

The groove and ridge cross section areas, as defined in Section 2.10, were evaluated by CLSM. Specific wear rate $(W)$, and the wear coefficient $(k)$ were calculated and plotted in Figure 14. These parameters provide additional information to understand the wear severity and the mechanisms that occurred. The calculated wear coefficients ranged from 0.1 to 0.4 . According to the classification of the wear condition as a function of wear coefficient $[76,77]$, they correspond to unlubricated sliding and wear by hard particles, i.e., the severe wear and abrasive mechanisms. The specific wear rate range, 0.5-1.9, confirmed the abrasive mechanism [78]. A combination of abrasive and adhesive wear can be supposed for the lowest values of specific wear rate detected, i.e., in the pure copper samples.

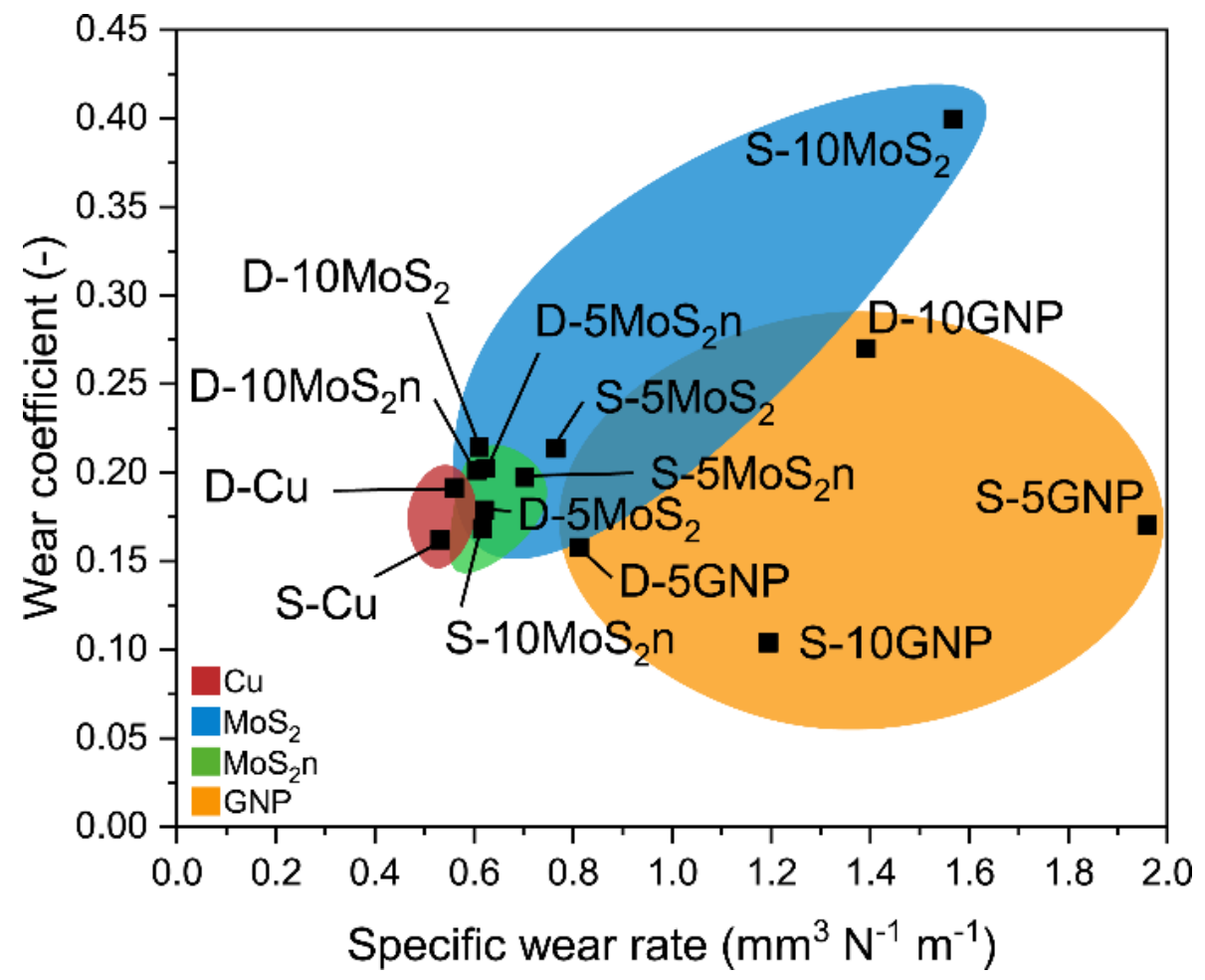

Figure 14. Wear coefficient and specific wear rate of the copper-solid lubricants composites.

\subsection{Scanning Electron Microscopy}

Scanning electron microscopy images were acquired with different magnifications for pure copper and the composites with $10 \mathrm{wt} \%$ of solid lubricant. Three magnifications were considered: $800 \times$, Figures 15 and 16 for the D- and S-samples, respectively, 5000×, Figure 17, and 10,000×, Figures 18 and 19 for the D- and S-samples, respectively. 

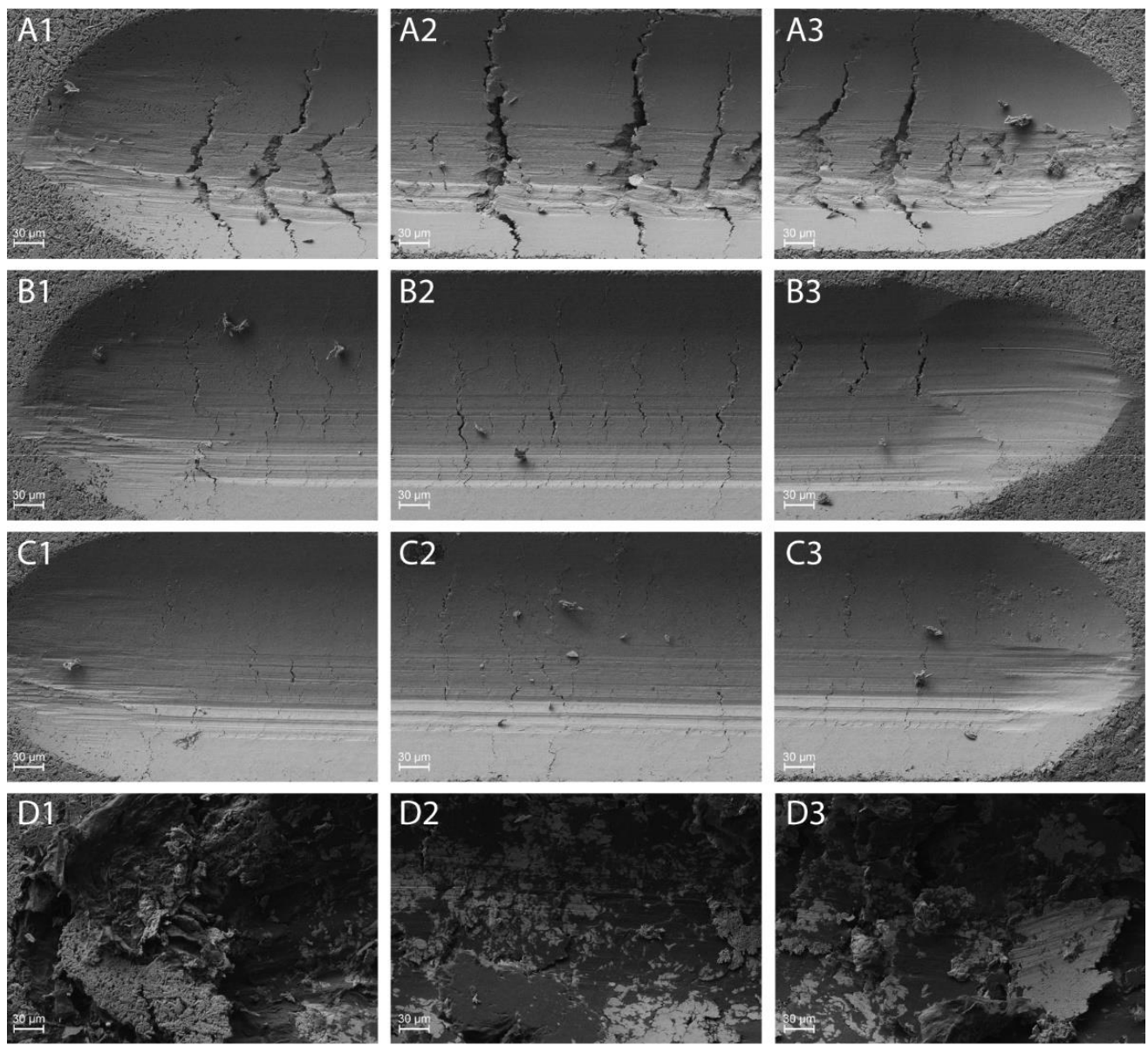

Figure 15. SEM images of (A) D-Cu, (B) D-10MoS 2 , (C) D-MoS 2 n, (D) D-10GNP samples scratch tracks, with magnification $800 \times$.
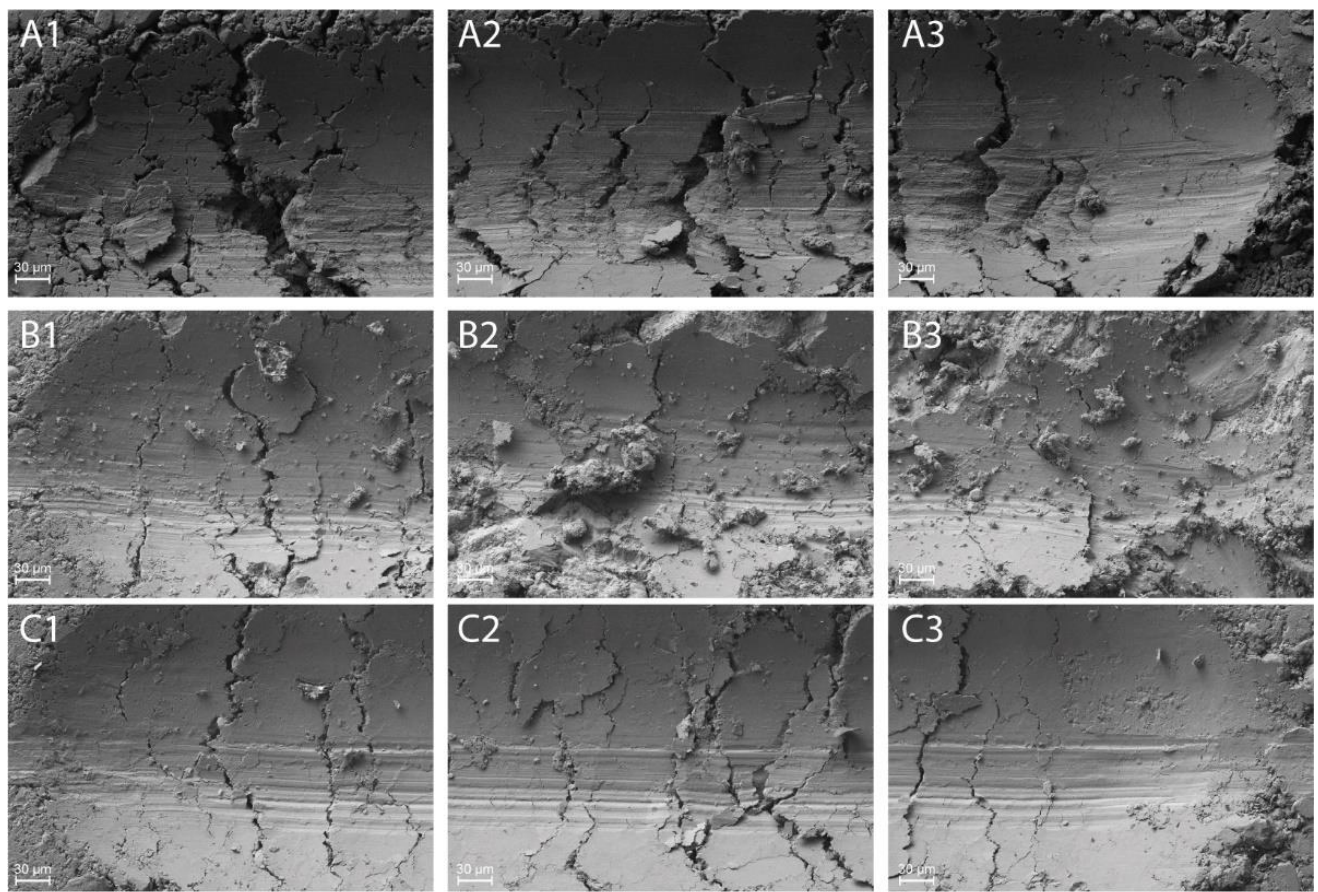

Figure 16. Cont. 

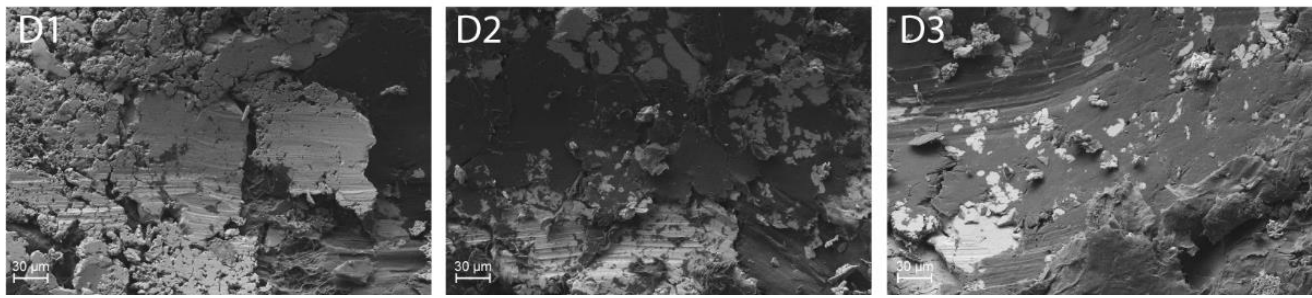

Figure 16. SEM images of (A) S-Cu, (B) S- $10 \mathrm{MoS}_{2}$, (C) S-MoS 2 n, (D) S-10GNP samples scratch tracks, with magnification $800 \times$.
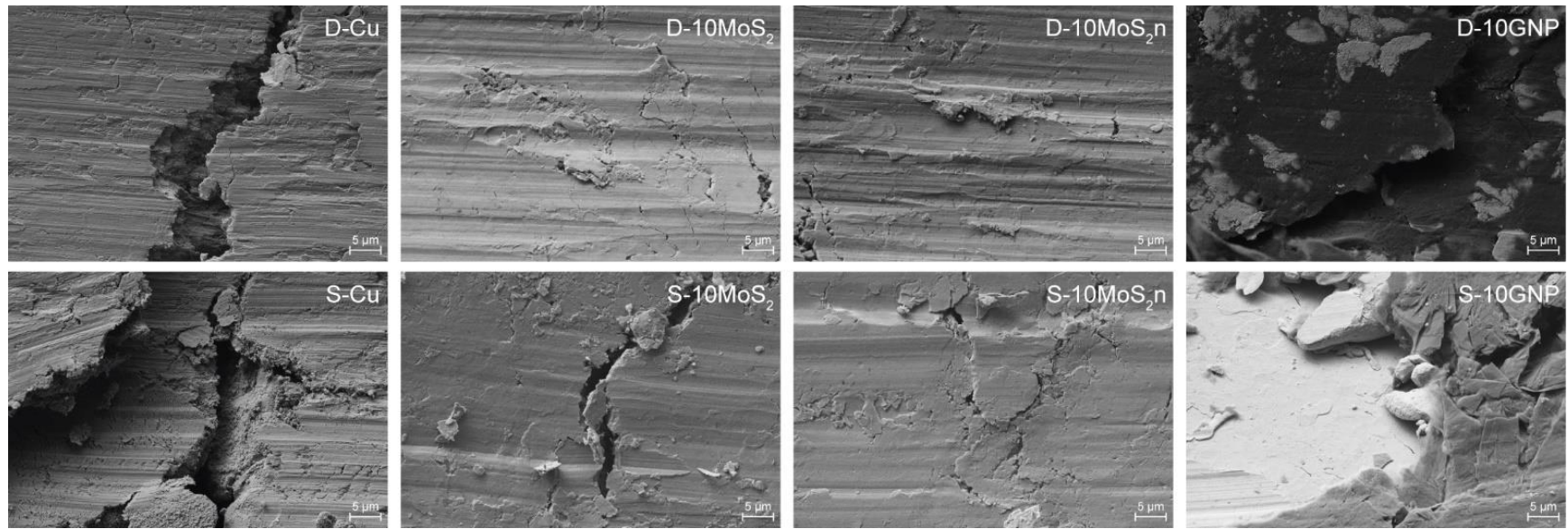

Figure 17. SEM images of (top) dendritic- and (bottom) spherical-copper based scratches with magnification $5000 \times$.
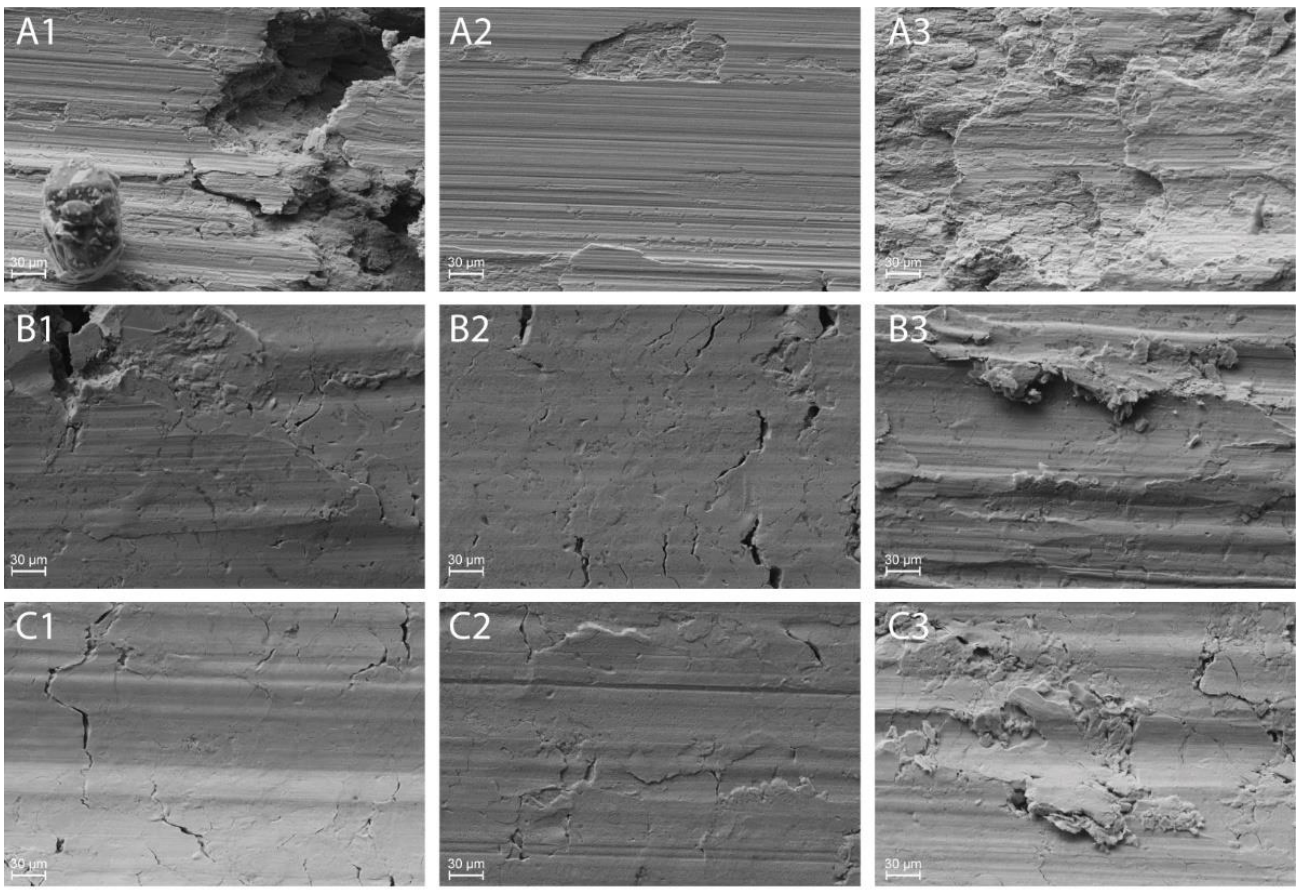

Figure 18. Cont. 

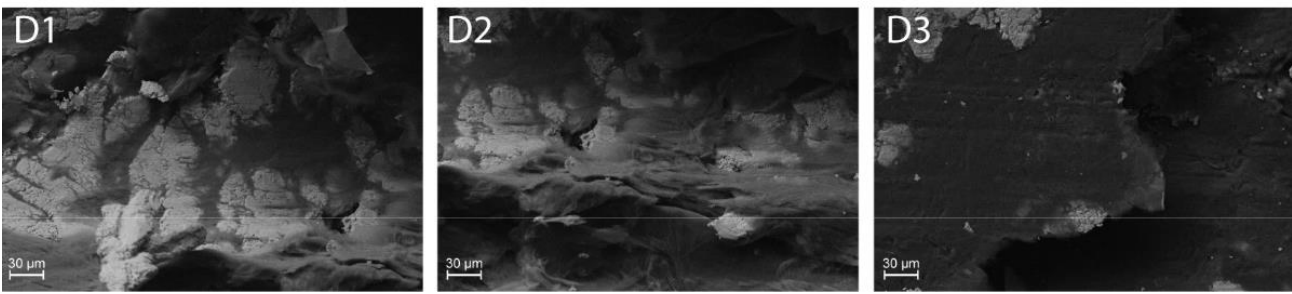

Figure 18. SEM images of (A) D-Cu, (B) D-10MoS 2 , (C) D-MoS 2 n, (D) D-10GNP sample scratch tracks, with magnification $10,000 \times$.
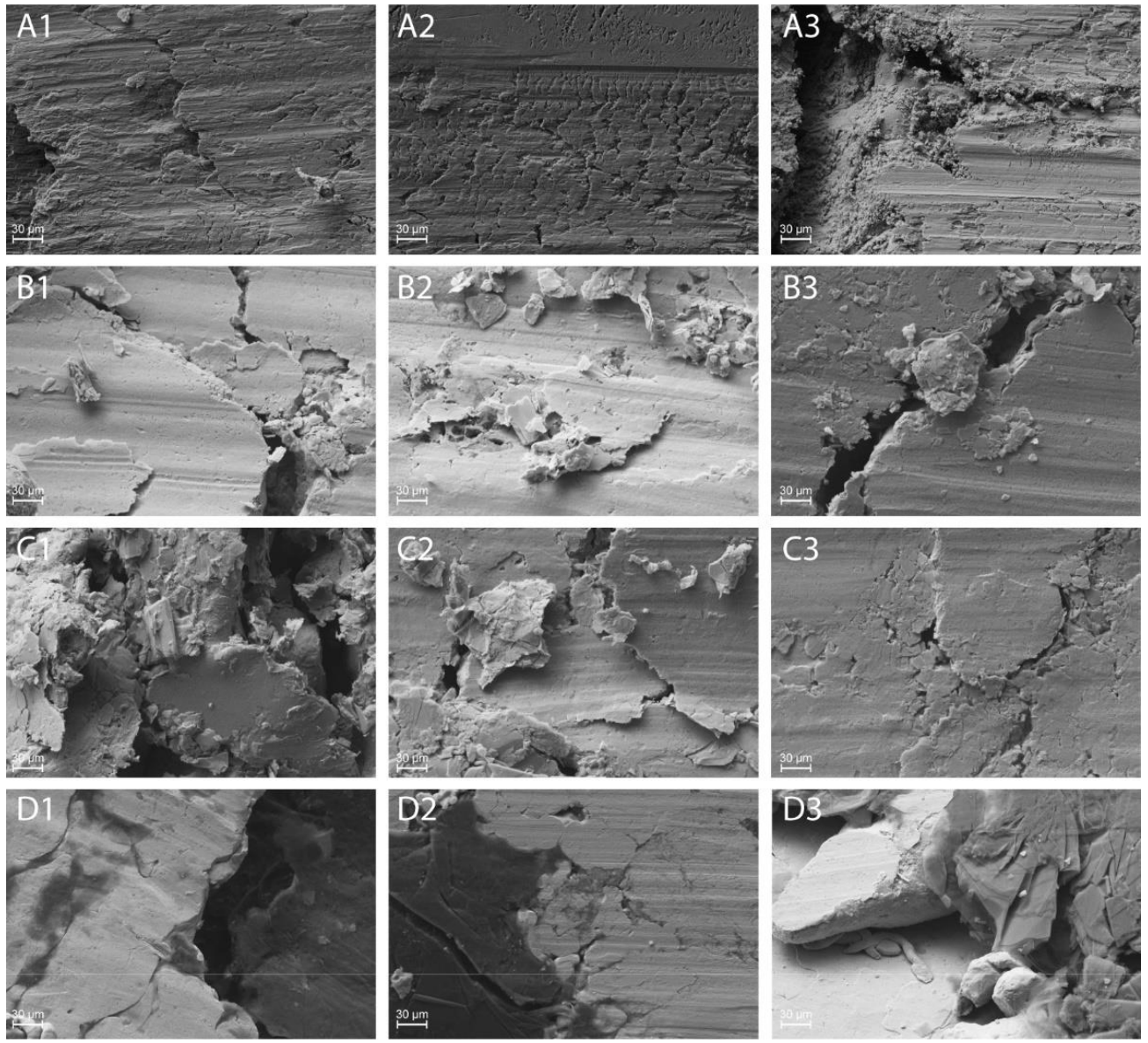

Figure 19. SEM images of (A) S-Cu, (B) S- $10 \mathrm{MoS}_{2}$, (C) S-MoS 2 n, (D) S-10GNP sample scratch tracks, with magnification $10,000 \times$.

The pure dendritic copper sample was characterized by the presence of micro-cracks, less debris and distinctive delamination layers visible at high magnification, Figure 18A.

The presence of micrometric $\mathrm{MoS}_{2}$ decreased the dimensions of the microcracks and led to the formation of a smoother and homogeneous surface. The nanometric composite accentuates the beneficial effects due to the lubricant presence: the micro-cracks become smaller and less frequent on the worn surface and the grooves due to abrasion are shallower. Big flake-like debris and a pile-up of materials distinguished the GNP scratches.

Delamination was present in all the spherical copper samples, probably due to a low cohesion between the matrix and the second phases. The weak interface between the constituent materials presents a preferential region for crack generation and propagation, determining the detachment of portions of materials. The S-MoS 2 sample exhibited microcracks, similar to those found in the pure copper, and high production of flaky debris. This sample had a high specific wear rate, Figure 14, meaning that a large amount of 
material was removed with respect to samples that had a comparable degree of penetration, Figure 12. This was probably due to the low cohesion of the spherical copper powder and the micrometric $\mathrm{MoS}_{2}$, that may also have hindered the correct sintering of the metallic powder, decreasing the resistance of the material to scratches. These features were limited in the nanometric $\mathrm{MoS}_{2}$ composite. As in the dendritic set, GNP was characterized by a significant displacement of material and debris formation along the scratch.

As indicated by the previous analysis, the abrasive wear mechanism was confirmed at different extents by the presence of the marked grooves parallel to the sliding direction visible in all the samples. The introduction of micrometric and nanometric $\mathrm{MoS}_{2}$ reduced the dimensions and limit the generation of the micro-cracks. Graphene nanoplatelets led to a higher production of flake-like debris with respect to the other composites. Surfaces of the spherical copper were more damaged than the dendritic copper samples due to a more severe delamination mechanism.

\section{Conclusions}

Two different copper powders, one dendritic and one spherical, were employed to produce, via metal powder metallurgy, six different composite materials with micrometric $\mathrm{MoS}_{2}$ powder, nanometric $\mathrm{MoS}_{2}$ powder, and graphene nanoplatelets in $5 \mathrm{wt} \%$ and $10 \mathrm{wt} \%$ concentrations. The materials were characterized by X-ray diffractometry and Raman spectroscopy, wettability, electrical resistivity and scratch tests; additional analyses were performed by confocal laser scanning microscopy and scanning electron microscopy. A summary of the main findings is hereby reported:

- No other phases were found, except for the constituent materials and copper oxide, whose presence was expected.

- All the tested samples exhibited hydrophobic behavior, with contact angles that ranged from $96^{\circ}$ to $136^{\circ}$.

- The micrometric and nanometric $\mathrm{MoS}_{2}$ composites recorded an increase of the electrical resistivity with respect to pure copper samples, proportional to the lubricant percentage. The composites with GNP showed a decreased electrical resistivity, reaching values between 51 and $96 \mathrm{n} \Omega \mathrm{m}$.

- The introduction of the solid lubricants decreased the friction coefficient from 0.8 in the pure copper samples to values around 0.4 .

- The GNP composites were characterized by the lowest scratch hardness.

- The pure copper, $\mathrm{MoS}_{2}$ and $\mathrm{MoS}_{2} \mathrm{n}$ composites exhibited similar main wear mechanisms, except for the GNP samples, which also experienced more severe wear.

- $\quad$ The presence of GNP slightly decreased the wear coefficient with respect to pure copper, while it substantially increased the specific wear rate. The $\mathrm{MoS}_{2}$ and $\mathrm{MoS}_{2} \mathrm{n}$ composites exhibited similar and lower values of the wear coefficient, with a slightly worse behavior reported for the S-10MoS 2 sample.

- To different extents, all the analyzed materials experienced an abrasive wear mechanism. The presence of the solid lubricants led to limited presence of grooves and microcracks and the formation of flake-like debris.

- The above-mentioned trends were found irrespective of the specific copper set (dendritic or spherical), although the spherical copper powder performed worse. This was probably due to the interaction with the solid lubricants that covered the spherical copper and may have hindered an efficient sintering process.

This study showed that the dendritic copper-based composites performed better than the corresponding spherical copper-based samples. GNP represents a valid alternative if electrical conductivity is required, but the tribological performance is below that of the other composites. Further analyses on the optimal concentration and production method are required. The addition of micrometric and nanometric $\mathrm{MoS}_{2}$, even if the specific wear rate and wear coefficients are slightly higher than those of pure copper samples, contributed to a decrease to the friction coefficient and the surface damage. The nanocomposites hindered 
the formation of microcracks on the surface and thus represent a good trade-off considering their different properties.

Author Contributions: Conceptualization, M.F., A.A. and O.H.; methodology, M.F., A.A., O.H. and L.A.; validation, G.D., L.A. and C.C.; formal analysis, M.F. and A.A.; investigation, M.F. and A.A.; resources, G.D., L.A., J.K. and C.C.; data curation, M.F., A.A., L.A., C.C. and G.D.; writing-original draft preparation, M.F. and A.A.; writing-review and editing, M.F., A.A., O.H., L.A., J.K., C.C. and G.D.; supervision, J.K., C.C. and G.D. All authors have read and agreed to the published version of the manuscript.

Funding: This research was funded by the European Institute of Innovation and Technology (EIT) Raw Materials (Berlin, Germany) with the project ADMA2-Practical training between Academia and Industry during doctoral studies, grant number 18252.

Institutional Review Board Statement: Not applicable.

Informed Consent Statement: Not applicable.

Data Availability Statement: Data are contained within the article.

Acknowledgments: The authors would like to thank the Italian company Logic S.p.A, who supplied some of the materials and instrumentation.

Conflicts of Interest: The authors declare no conflict of interest.

\section{References}

1. Natarajan, N.; Krishnaraj, V.; Davim, J.P. Metal Matrix Composites—Synthesis, Wear Characteristics, Machinability Study of MMC Brake Drum; Davim, J.P., Ed.; SpringerBriefs in Applied Sciences and Technology; Springer International Publishing: Cham, Switzerland, 2015; ISBN 978-3-319-02984-9.

2. Erdemir, A. Solid lubricants and self-lubricating films. Mod. Tribol. Handb. Vol. One Princ. Tribol. 2000, 2, 787-825. [CrossRef]

3. Vazirisereshk, M.R.; Martini, A.; Strubbe, D.A.; Baykara, M.Z. Solid Lubrication with MoS2: A Review. Lubricants 2019 , 7, 57. [CrossRef]

4. Serles, P.; Gaber, K.; Pajovic, S.; Colas, G.; Filleter, T. High Temperature Microtribological Studies of MoS2 Lubrication for Low Earth Orbit. Lubricants 2020, 8, 49. [CrossRef]

5. Lince, J.R. Effective Application of Solid Lubricants in Spacecraft Mechanisms. Lubricants 2020, 8, 74. [CrossRef]

6. Busch, C. Solid Lubrication. In Lubricants and Lubrication; Mang, T., Dresel, W., Eds.; Wiley-VCH Verlag GmbH \& Co. KGaA: Weinheim, Germany, 2007; pp. 694-714. ISBN 9783527314973.

7. Wang, Y.A.; Li, J.X.; Yan, Y.; Qiao, L.J. Effect of electrical current on tribological behavior of copper-impregnated metallized carbon against a CuCrZr alloy. Tribol. Int. 2012, 50, 26-34. [CrossRef]

8. Gradt, T.; Schneider, T. Tribological performance of MoS2 coatings in various environments. Lubricants 2016, 4, 32. [CrossRef]

9. Marian, M.; Berman, D.; Rota, A.; Jackson, R.L.; Rosenkranz, A. Layered 2D Nanomaterials to Tailor Friction and Wear in Machine Elements-A Review. Adv. Mater. Interfaces 2021, 9, 2101622. [CrossRef]

10. Freschi, M.; Di Virgilio, M.; Zanardi, G.; Mariani, M.; Lecis, N.; Dotelli, G. Employment of Micro- and Nano-WS2 structures to enhance the tribological properties of copper matrix composites. Lubricants 2021, 9, 53. [CrossRef]

11. An, V.; Irtegov, Y. Tribological properties of nanolamellar MoS2 doped with copper nanoparticles. J. Nanomater. 2014, $2014,1-7$. [CrossRef]

12. Zhang, L.; Duan, Z.; Zhu, H.; Yin, K. Advances in synthesizing copper/graphene composite material. Mater. Manuf. Process. 2017, 32, 475-479. [CrossRef]

13. Pape, F.; Poll, G. Investigations on graphene platelets as dry lubricant and as grease additive for sliding contacts and rolling bearing application. Lubricants 2020, 8, 3. [CrossRef]

14. Rivera, N.A.; Neves, G.O.; Giacomelli, R.O.; Salvaro, D.; Binder, C.; Klein, A.N.; Biasoli de Mello, J.D. Dry tribological performance of nanostructured 2D turbostratic graphite particles derived from boron and chromium carbides. Wear 2021, $477,203842$. [CrossRef]

15. Sarno, M.; Scarpa, D.; Senatore, A.; Mustafa, W.A.A. rGO/GO nanosheets in tribology: From the state of the art to the future prospective. Lubricants 2020, 8, 31. [CrossRef]

16. Miura, K.; Kamiya, S. Observation of the Amontons-Coulomb law on the nanoscale: Frictional forces between MoS2 flakes and MoS2 surfaces. Europhys. Lett. 2002, 58, 610-615. [CrossRef]

17. Miralrio, A.; Rangel, E.; Castro, M. Activation of $\mathrm{MoS}_{2}$ monolayers by substitutional copper and silver atoms embedded in sulfur vacancies: A theoretical study. Appl. Surf. Sci. 2019, 481, 611-624. [CrossRef]

18. Evans, D.C.; Senior, G.S. Self-lubricating materials for plain bearings. Tribol. Int. 1982, 15, 243-248. [CrossRef]

19. Grandin, M. Tribology of Metal-Graphite Composites: A Study of Sliding Electrical Contact Surfaces; Acta Universitatis Upsaliensis: Upsala, Sweden, 2017; Volume 1565, ISBN 978-91-513-0079-5, ISSN 16516214. 
20. Noh, H.J.; Kim, J.W.; Lee, S.M.; Jang, H. Effect of grain size on the electrical failure of copper contacts in fretting motion. Tribol. Int. 2017, 111, 39-45. [CrossRef]

21. Taher, M.; Mao, F.; Berastegui, P.; Andersson, A.M.; Jansson, U. Tuning tribological, mechanical and electrical properties of Ag-X $(\mathrm{X}=\mathrm{Al}, \mathrm{In}, \mathrm{Sn})$ alloys. Tribol. Int. 2018, 125, 121-127. [CrossRef]

22. Kang, S. Sintering-Densification, Grain Growth, and Microstructure; Elsevier Butterworth-Heinemann: Oxford, UK, 2005; ISBN 978-07-506-6385-4.

23. Freschi, M.; Di Virgilio, M.; Haiko, O.; Mariani, M.; Andena, L.; Lecis, N.; Kömi, J.; Dotelli, G. Investigation of second phase concentration effects on tribological and electrical properties of $\mathrm{Cu}-\mathrm{WS} 2$ composites. Tribol. Int. 2022, 166, 107357. [CrossRef]

24. Taher, M.; Mao, F.; Berastegui, P.; Andersson, A.M.; Jansson, U. The influence of chemical and phase composition on mechanical, tribological and electrical properties of Silver-Aluminum alloys. Tribol. Int. 2018, 119, 680-687. [CrossRef]

25. Xie, X.L.; Zhang, L.; Xiao, J.K.; Qian, Z.Y.; Zhang, T.; Zhou, K.C. Sliding electrical contact behavior of AuAgCu brush on Au plating. Trans. Nonferrous Met. Soc. China 2015, 25, 3029-3036. [CrossRef]

26. Slade, P.G. Electrical Contacts: Principles and Applications, 2nd ed.; Slade, P.G., Ed.; CRC Press: Boca Raton, FL, USA, 2014; ISBN 9781315216829

27. Kubota, Y.; Nagasaka, S.; Miyauchi, T.; Yamashita, C.; Kakishima, H. Sliding wear behavior of copper alloy impregnated C/C composites under an electrical current. Wear 2013, 302, 1492-1498. [CrossRef]

28. Argibay, N.; Bares, J.A.; Keith, J.H.; Bourne, G.R.; Sawyer, W.G. Copper-beryllium metal fiber brushes in high current density sliding electrical contacts. Wear 2010, 268, 1230-1236. [CrossRef]

29. Ren, W.; Wang, P.; Song, J.; Zhai, G. Effects of current load on wear and fretting corrosion of gold-plated electrical contacts. Tribol. Int. 2014, 70, 75-82. [CrossRef]

30. Ren, W.; Wang, P.; Fu, Y.; Pan, C.; Song, J. Effects of temperature on fretting corrosion behaviors of gold-plated copper alloy electrical contacts. Tribol. Int. 2015, 83, 1-11. [CrossRef]

31. Sawa, K.; Shobert, E. Sliding Electrical Contacts (Graphitic Type Lubrication). In Electrical Contacts; Slade, P.G., Ed.; CRC Press: Boca Raton, FL, USA, 2014; pp. 1041-1079. ISBN 9781315216829.

32. Qian, G.; Feng, Y.; Chen, F.; Liu, W.; Zhang, X.; Liu, Y. Effect of current polarity on electrical sliding wear behavior of Cu-WS2graphite-WS2 nanotube composites in air and vacuum conditions. Sci. China Technol. Sci. 2013, 56, 2839-2846. [CrossRef]

33. Hu, Z.L.; Chen, Z.H.; Xia, J.T. Study on surface film in the wear of electrographite brushes against copper commutators for variable current and humidity. Wear 2008, 264, 11-17. [CrossRef]

34. Xiao, J.; Zhang, L.; Zhou, K.; Wang, X. Microscratch behavior of copper-Graphite composites. Tribiology Int. 2013, 57, 38-45. [CrossRef]

35. Jiang, X.; Song, J.; Su, Y.; Zhang, Y.; Hu, L. Novel Design of Copper-Graphite Self-Lubricating Composites for Reliability Improvement Based on 3D Network Structures of Copper Matrix. Tribol. Lett. 2018, 66, 1-11. [CrossRef]

36. Zhang, X.; Chen, Y.; Wu, K.; Chao, Y.; Dong, P.; Yang, W.; Zhan, Y. Fabrication and tribological properties of copper matrix composite with short carbon fiber/reduced graphene oxide filler. Tribol. Int. 2016, 103, 406-411. [CrossRef]

37. Chen, F.; Ying, J.; Wang, Y.; Du, S.; Liu, Z.; Huang, Q. Effects of graphene content on the microstructure and properties of copper matrix composites. Carbon N. Y. 2016, 96, 836-842. [CrossRef]

38. Gao, X.; Yue, H.; Guo, E.; Zhang, S.; Yao, L.; Lin, X.; Wang, B.; Guan, E. Tribological properties of copper matrix composites reinforced with homogeneously dispersed graphene nanosheets. J. Mater. Sci. Technol. 2018, 34, 1925-1931. [CrossRef]

39. Chmielewski, M.; Michalczewski, R.; Piekoszewski, W.; Kalbarczyk, M. Tribological behaviour of copper-graphene composite materials. Key Eng. Mater. 2016, 674, 219-224. [CrossRef]

40. Koti, V.; George, R.; Koppad, P.G.; Murthy, K.V.S.; Shakiba, A. Friction and wear characteristics of copper nanocomposites reinforced with uncoated and nickel coated carbon nanotubes. Mater. Res. Express 2018, 5, 095607. [CrossRef]

41. Furlan, K.P.; de Mello, J.D.B.; Klein, A.N. Self-lubricating composites containing MoS2: A review. Tribol. Int. 2018, 120, 280-298. [CrossRef]

42. Shangguan, B.; Zhang, Y.Z.; Xing, J.D.; Sun, L.M.; Chen, Y. Wear behavior of electrified copper-MoS 2 powder metallurgy materials under dry sliding. J. Comput. Theor. Nanosci. 2012, 9, 1458-1461. [CrossRef]

43. Xiao, J.K.; Zhang, W.; Liu, L.M.; Zhang, L.; Zhang, C. Tribological behavior of copper-molybdenum disulfide composites. Wear 2017, 384-385, 61-71. [CrossRef]

44. Wang, A.-Q.; Liang, T.-T.; Ma, D.-Q.; Xie, J.-P. Microstructures and Properties of Sintered Cu-MoS2/Cu Functional Gradient Materials. Adv. Eng. Res. 2017, 100, 537-542. [CrossRef]

45. Moazami-Goudarzi, M.; Nemati, A. Tribological behavior of self lubricating Cu/MoS2 composites fabricated by powder metallurgy. Trans. Nonferrous Met. Soc. China 2018, 28, 946-956. [CrossRef]

46. Vincent, C.; Silvain, J.F.; Heintz, J.M.; Chandra, N. Effect of porosity on the thermal conductivity of copper processed by powder metallurgy. J. Phys. Chem. Solids 2012, 73, 499-504. [CrossRef]

47. Briscoe, B.J.; Sinha, S.K. Scratch Resistance and Localised Damage Characteristics of Polymer Surfaces-A Review. Materwiss. Werksttech. 2003, 34, 989-1002. [CrossRef]

48. Kurkcu, P.; Andena, L.; Pavan, A. An experimental investigation of the scratch behaviour of polymers: 1 . Influence of ratedependent bulk mechanical properties. Wear 2012, 290-291, 86-93. [CrossRef] 
49. Gao, C.; Liu, M. Effects of Normal Load on the Coefficient of Friction by Microscratch Test of Copper with a Spherical Indenter. Tribol. Lett. 2019, 67, 1-12. [CrossRef]

50. Kurkcu, P.; Andena, L.; Pavan, A. An experimental investigation of the scratch behaviour of polymers-2: Influence of hard or soft fillers. Wear 2014, 317, 277-290. [CrossRef]

51. Makin Metal Powders Laboratory Report (Certificate of Analysis); John Wiley \& Sons: Rochdale, UK, 2018.

52. Pometon Test Report; John Wiley \& Sons: Maerne, Italy, 2018.

53. Basso Peressut, A.; Latorrata, S.; Gallo Stampino, P.; Dotelli, G. Development of self-assembling sulfonated graphene oxide membranes as a potential proton conductor. Mater. Chem. Phys. 2021, 257, 123768. [CrossRef]

54. Archard, J.F. Contact and rubbing of flat surfaces. J. Appl. Phys. 1953, 24, 981-988. [CrossRef]

55. Raffi, M.; Mehrwan, S.; Bhatti, T.M.; Akhter, J.I.; Hameed, A.; Yawar, W.; ul Hasan, M.M. Investigations into the antibacterial behavior of copper nanoparticles against Escherichia coli. Ann. Microbiol. 2010, 60, 75-80. [CrossRef]

56. Gopika, M.S.; Bindhu, B. Preparation and characterization of few layered mos2 nano flakes. Int. J. Recent Technol. Eng. 2019, 8 , 146-148. [CrossRef]

57. Wei, R.; Zhang, H.; He, X.; Hu, Z.; Tian, X.; Xiao, Q.; Chen, Z.; Qiu, J. Versatile preparation of ultrathin MoS2 nanosheets with reverse saturable absorption response. Opt. Mater. Express 2015, 5, 1807. [CrossRef]

58. Gutić, S. Surface Charge Storage Properties of Selected Graphene Samples in pH-neutral Aqueous Solutions of Alkali Metal Chlorides-Particularities and Universalities. Int. J. Electrochem. Sci. 2016, 11, 8662-8682. [CrossRef]

59. Kalita, G.; Ayhan, M.E.; Sharma, S.; Shinde, S.M.; Ghimire, D.; Wakita, K.; Umeno, M.; Tanemura, M. Low temperature deposited graphene by surface wave plasma CVD as effective oxidation resistive barrier. Corros. Sci. 2014, 78, 183-187. [CrossRef]

60. Prabhakaran, G.; Murugan, R. Room temperature ferromagnetic properties of $\mathrm{Cu}_{2} \mathrm{O}$ microcrystals. J. Alloys Compd. 2013, 579, 572-575. [CrossRef]

61. Liang, L.; Meunier, V. First-principles Raman spectra of $\mathrm{MoS}_{2}, \mathrm{WS}_{2}$ and their heterostructures. Nanoscale. 2014, 6, 5394-5401. [CrossRef] [PubMed]

62. Blanco, É; Afanasiev, P.; Berhault, G.; Uzio, D.; Loridant, S. Resonance Raman spectroscopy as a probe of the crystallite size of MoS2 nanoparticles. Comptes Rendus Chim. 2016, 19, 1310-1314. [CrossRef]

63. Kim, H.J.; Kim, D.; Jung, S.; Bae, M.H.; Yun, Y.J.; Yi, S.N.; Yu, J.S.; Kim, J.H.; Ha, D.H. Changes in the Raman spectra of monolayer MoS2 upon thermal annealing. J. Raman Spectrosc. 2018, 49, 1938-1944. [CrossRef]

64. Isac, A.; Duta, A.; Kriza, A.; Enesca, A.; Nanu, M. The growth of CuS thin films by Spray Pyrolysis. J. Phys. Conf. Ser. 2007, 61, 096. [CrossRef]

65. Bhatt, V.; Kumar, M.; Yun, J.H. Unraveling the photoconduction characteristics of single-step synthesized CuS and Cu9S5 micro-flowers. J. Alloys Compd. 2022, 891, 161940. [CrossRef]

66. Anastassakis, E.; Perry, C.H. Light scattering and ir measurements in XS2 pryite-type compounds. J. Chem. Phys. 2008, 64, 3604. [CrossRef]

67. Fu, X.; Yang, G.; Sun, J.; Zhou, J. Vibrational Spectra of Copper Sulfate Hydrates Investigated with Low-Temperature Raman Spectroscopy and Terahertz Time Domain Spectroscopy. J. Phys. Chem. A 2012, 116, 7314-7318. [CrossRef]

68. Ferrari, A.C.; Meyer, J.C.; Scardaci, V.; Casiraghi, C.; Lazzeri, M.; Mauri, F.; Piscanec, S.; Jiang, D.; Novoselov, K.S.; Roth, S.; et al. Raman Spectrum of Graphene and Graphene Layers. Phys. Rev. Lett. 2006, 97, 187401. [CrossRef]

69. Nanda, S.S.; Kim, M.J.; Yeom, K.S.; An, S.S.A.; Ju, H.; Yi, D.K. Raman spectrum of graphene with its versatile future perspectives. TrAC Trends Anal. Chem. 2016, 80, 125-131. [CrossRef]

70. Wu, J.B.; Lin, M.L.; Cong, X.; Liu, H.N.; Tan, P.H. Raman spectroscopy of graphene-based materials and its applications in related devices. Chem. Soc. Rev. 2018, 47, 1822-1873. [CrossRef] [PubMed]

71. Atkinson, H.H. Handbook of Chemistry and Physics. Phys. Bull. 1963, 14, 308. [CrossRef]

72. Kovalchenko, A.M.; Fushchich, O.I.; Danyluk, S. The tribological properties and mechanism of wear of Cu-based sintered powder materials containing molybdenum disulfide and molybdenum diselenite under unlubricated sliding against copper. Wear 2012, 290-291, 106-123. [CrossRef]

73. Kato, H.; Takama, M.; Iwai, Y.; Washida, K.; Sasaki, Y. Wear and mechanical properties of sintered copper-tin composites containing graphite or molybdenum disulfide. Wear 2003, 255, 573-578. [CrossRef]

74. Kayaba, T.; Hokkirigawa, K.; Kato, K. Analysis of the abrasive wear mechanism by successive observations of wear processes in a scanning electron microscope. Wear 1986, 110, 419-430. [CrossRef]

75. Hokkirigawa, K.; Kato, K. An experimental and theoretical investigation of ploughing, cutting and wedge formation during abrasive wear. Tribol. Int. 1988, 21, 51-57. [CrossRef]

76. Khalaj, M.; Zarabi Golkhatmi, S.; Alem, S.A.A.; Baghchesaraee, K.; Hasanzadeh Azar, M.; Angizi, S. Recent Progress in the Study of Thermal Properties and Tribological Behaviors of Hexagonal Boron Nitride-Reinforced Composites. J. Compos. Sci. 2020, 4, 116. [CrossRef]

77. Stachowiak, G.W. (Ed.) Wear-Materials, Mechanisms and Practice; John Wiley \& Sons Ltd: Chichester, UK, $2005 ;$ ISBN 9780470017029.

78. Axén, N.; Jacobson, S.; Hogmark, S. Friction and Wear Measurement Techniques. In Modern Tribology Handbook; CRC Press: Boca Raton, FL, USA, 2001; ISBN 0849384036. 